\title{
Morphological and molecular analysis of Willowsia nigromaculata (Collembola, Entomobryidae, Entomobryinae) reveals a new cryptic species from the United States
}

\author{
Nikolas G. CIPOLA ${ }^{1, *} \&$ Aron D. KATZ ${ }^{2}$ \\ ${ }^{1}$ Laboratório de Sistemática e Ecologia de Invertebrados do Solo, Instituto Nacional de Pesquisas da \\ Amazônia - INPA, CPEN. Av. André Araújo, 2936, Aleixo, CEP 69067-375, Manaus, AM, Brazil. \\ ${ }^{2}$ Engineer Research and Development Center, 2902 Newmark Drive, Champaign, IL 61826, USA. \\ ${ }^{2}$ Illinois Natural History Survey, Prairie Research Institute, University of Illinois at Urbana- \\ Champaign, 1816 South Oak Street, Champaign, IL 61820, USA.
}

*Corresponding author: nikolasge@gmail.com

2Email: aronkatz@illinois.edu

\footnotetext{
${ }^{1}$ urn:1sid:zoobank.org:author:70DD3D02-82A6-466D-B222-8A30DF9D933F

${ }^{2}$ urn:Isid:zoobank.org:author:72328BBA-0AF8-41D9-813C-A21EEC7C90C5
}

\begin{abstract}
Commonly reported as a household pest throughout the northern hemisphere, Willowsia nigromaculata (Lubbock) is among the most abundant and widely distributed springtails. However, taxonomic uncertainty due to incomplete morphological descriptions based on specimens from different continents may lead to incorrect identifications and/or prevent the recognition of distinct lineages within this morphospecies. Here, we perform the first comprehensive morphological and genetic comparison between W. nigromaculata specimens collected from North America and Europe. Morphological and genetic evidence reveals that populations in the United States and France represent two distinct nigromaculata-like species, but a phylogenetic analysis indicates both species may also be present in Canada. Based on these results, we redescribe $W$. nigromaculata from France, provide a description for Willowsia neonigromaculata sp. nov. from the United States, and propose new diagnostic characters for their separation, including the number of inner appendages on the maxillary sublobal plate. We also highlight the need for morphological and molecular investigations of additional populations to better understand the diversity and distribution of $W$. nigromaculata and related species.
\end{abstract}

Keywords. Chaetotaxy, phylogeny, new species, Willowsiinae, Willowsia neonigromaculata sp. nov.

Cipola N.G. \& Katz A.D. 2021. Morphological and molecular analysis of Willowsia nigromaculata (Collembola, Entomobryidae, Entomobryinae) reveals a new cryptic species from the United States. European Journal of Taxonomy 739: 92-116. https://doi.org/10.5852/ejt.2021.739.1269

\section{Introduction}

Originally described as Seira nigromaculata Lubbock, 1873, and later designated as the type species for the genus Willowsia Shoebothan, 1917, Willowsia nigromaculata (Lubbock, 1873) is considered to be 
among the most abundant and widely distributed species of Collembola, occurring in human structures such as homes, cellars, windowsills, greenhouses, and grain silos throughout the northern hemisphere (Guthrie 1903; Maynard 1951; Scott 1991; Christiansen \& Bellinger 1998; Fjellberg 2007; Zhang et al. 2011; Bellinger et al. 2020). Despite being a common household and agricultural pest, the taxonomic status of this species remains uncertain.

Until recently, W. nigromaculata was identified primarily by color pattern (Gisin 1960; Stach 1967; Fjellberg 2007), especially in North America (Guthrie 1903; Maynard 1951; Christiansen \& Bellinger 1998). Color pattern has been shown to be a useful species-level diagnostic character in certain cases (Soto-Adames 2002; Katz et al. 2015a; Ding et al. 2018), but other studies also highlight the importance of including chaetotaxy and other morphological characters, in addition to color pattern, for Entomobryinae species diagnosis (Jordana 2012; Katz et al. 2015b). Szeptycki (1979), Christiansen \& Bellinger (1980), and Zhang et al. (2011) provided modern descriptions of dorsal chaetotaxy for populations of W. nigromaculata in Poland, United States of America (USA), and France, respectively, but many important characters were not revealed, including head chaetotaxy, mouthparts, collophore and manubrium. Katz (2017) later provided descriptions of some of these missing characters based on specimens collected in the USA but did not examine European material for comparison.

Incomplete species descriptions of $W$. nigromaculata based on specimens collected from different continents may prevent the recognition of distinct species, and consequently, species identifications could be misleading and/or populations may be incorrectly assumed to be introduced on other continents. In response to this concern, we conduct the first comprehensive morphological and genetic comparisons of $W$. nigromaculata with specimens collected from both North America and Europe to (1) determine whether morphologically and/or genetically distinct lineages are present within W. nigromaculata, (2) determine if morphological and/or genetic differences correspond to collection locality, (3) provide taxonomic redescriptions of $W$. nigromaculata and any potential new species and (4) reveal new diagnostic characters for the identification of any distinct lineages uncovered within W. nigromaculata.

\section{Material and methods}

\section{Morphological analysis}

Specimens preserved in $92-95 \%$ ethanol and identified as Willowsia nigromaculata from Paris, France and Illinois, USA, were cleared with Nesbitt's solution and then mounted on glass slides in Hoyer's medium following the procedures described by Jordana et al. (1997) in preparation for light microscopy. Specimens in ethanol gel were photographed using a stereo microscope M165C attached to a DFC420 digital camera with a dome as presented in Kawada \& Buffington (2016). Photographs were digitized using Application Suite ver. 3.4.1. For scanning electron microscopy (SEM), specimens were transferred to absolute ethanol and critical point dried after sputter-coating with gold using the equipment BALTEC CPD 030 and BAL-TEC SPD 050, respectively. The images were made using a LEO VP 435 scanning electron microscope. The material is deposited in the Invertebrate Collection of the National Institute of Amazonian Research (INPA), Brazil, and the Illinois Natural History Survey (INHS) in Champaign, IL, United States.

The terminology used in descriptions mainly follows: clypeal chaetotaxy after Yoshii \& Suhardjono (1992); labral chaetotaxy after Cipola et al. (2014); labial papillae, maxillary palp and basolateral and basomedian labial fields after Fjellberg (1999), using Gisin's system (1967) to a 1-5 chaetae labels; postlabial chaetotaxy after Chen \& Christiansen (1993); subcoxae outer chaetotaxy after Yosii (1959); and unguiculus lamellae after Hüther (1986). The head dorsal chaetotaxy follows Mari-Mutt (1979) and 
body after Szeptycki (1979), both adapted from Soto-Adames (2008) and Katz (2017); and specialized chaetae (S-chaetae) after Zhang \& Deharveng (2015). Macrochaetotaxy simplified formula follows Gisin (1967) and Cipola et al. (2020) with modifications. Symbols used to depict the chaetotaxy are presented in Figure 1. Chaetae of uncertain homology are followed by a question mark (?). Chaetotaxy all given left side of body only.

\section{Abbreviations}

$\begin{array}{lll}\text { Abd I-VI } & = & \text { abdominal segments } \\ \text { ae } & = & \text { antero-external lamella } \\ \text { ai } & = & \text { antero-internal lamella } \\ \text { Ant I-IV } & = & \text { antennal segments } \\ \text { a.t. } & = & \text { apical tooth of unguis } \\ \text { b.c. } & = & \text { basal chaeta } \\ \text { b.t. } & = & \text { basal tooth of unguis } \\ \text { 1.p. } & = & \text { lateral process of labial papilla E } \\ \text { mac } & = & \text { macrochaeta, -ae } \\ \text { mes } & = & \text { mesochaeta, -ae } \\ \text { m.t. } & = & \text { apical tooth of unguis } \\ \text { pe } & = & \text { postero-external lamella } \\ \text { pi } & = & \text { postero-internal lamella } \\ \text { psp } & = & \text { pseudopore, -es } \\ \text { ms } & = & \text { specialized microchaeta } \\ \text { sb. } & = & \text { sublobal chaetae } \\ \text { sens } & = & \text { specialised ordinary chaetae, }- \text { ae } \\ \text { Th II-III } & = & \text { thoracic segments } \\ \text { t.a. } & = & \text { terminal appendage }\end{array}$

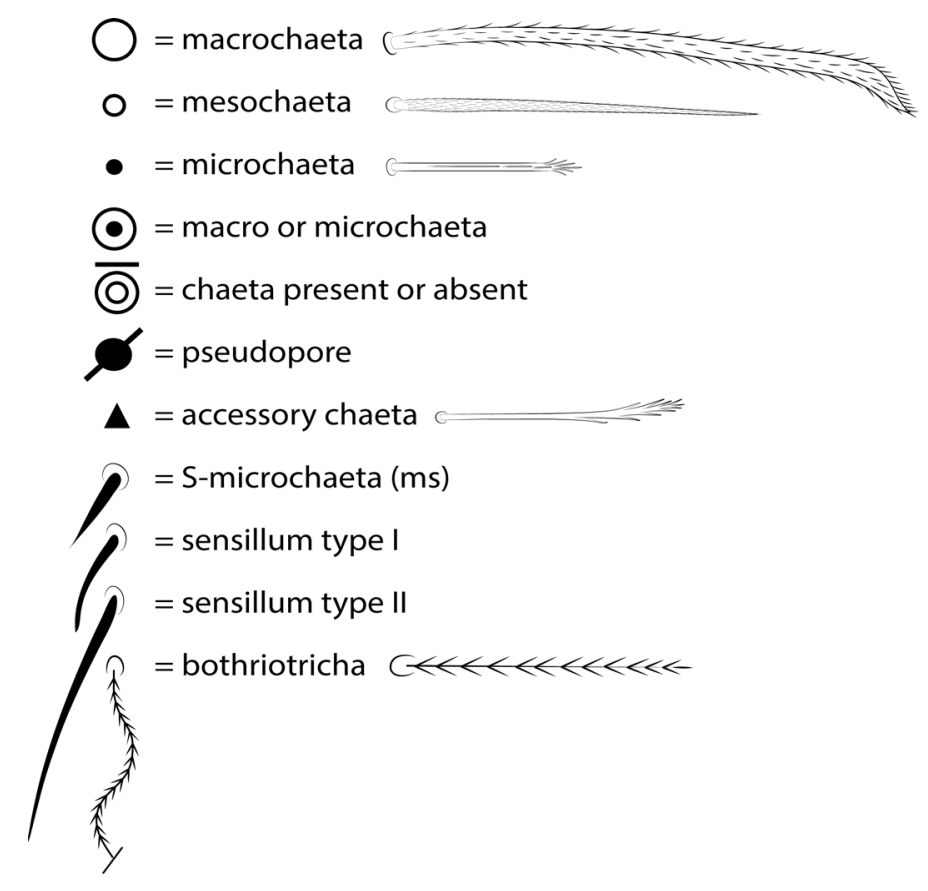

Fig. 1. Symbols used in dorsal chaetotaxy description of species of Willowsia Shoebothan, 1917. 


\section{Genetic analysis}

Forty mitochondrial cytochrome oxidase subunit 1 (COI) gene sequences, representing ten Entomobryinae genera, were downloaded from NCBI GenBank and used for genetic analysis (Table 1). Genetic variation within $W$. nigromaculata was evaluated using sequences of six specimens identified as W. nigromaculata: one from Dixon Springs Agricultural Center, Pope County, Illinois, USA (Katz et al. 2015a, 2015b); one from Teillet, France (Ding et al. 2018); one from Brockville, Canada (deWaard et al. 2019); and three from Toronto, Canada (deWaard et al. 2019). To provide a more comprehensive approach for assessing genetic variation within Entomobryinae, a subfamily rife with para- and polyphyletic genera (Zhang et al. 2014a, 2014b, 2015, 2016, 2017; Katz et al. 2015b, 2017; Zhang \& Deharveng 2015; Ding et al. 2018), we augmented our dataset with species from the Entomobryinae genera Coecobyra (1), Drepanura (1), Entomobrya (16), Entomobryoides (1), Homidia (2), Lepidodens (1), and Sinhomidia (1), in addition to other Willowsia species (8). Lastly, we included three species in the genera Lepidocyrtoides (2) and Lepidosira (1) to serve as phylogenetic outgroups as they have been shown to comprise the sister lineage to all other Entomobryinae (Nunes et al. 2019; Godeiro et al. 2020). Sequences were aligned using the G-INSI-i alignment method implemented in MAFFT ver. 7.273 (Katoh \& Standley 2013).

Uncorrected pairwise COI distances were calculated in Geneious Prime ver. 2020.0.4 (https://www.geneious.com) and plotted in R ver. 3.6.3 (R Core Team 2020) to (1) characterize genetic variation within $W$. nigromaculata, (2) compare the genetic variation within $W$. nigromaculata with variation observed between other species of Entomobryinae, and (3) identify potential gaps in the distribution of genetic variation which may indicate the presence of both inter- and intra-specific variation within $W$. nigromaculata.

Bayesian and maximum likelihood approaches were employed to estimate phylogenetic relationships among Entomobryinae species to determine if distinct and divergent lineages are present within W. nigromaculata and if they correspond with differences in collection locality and/or morphology. PartitionFinder2 ver. 2.2.1 (Lanfear et al. 2017) was used to determine the appropriate models of sequence evolution and partitioning scheme. Bayesian analysis was performed using MrBayes ver. 3.2.7 (Ronquist et al. 2012) with the following parameters: codon positons 1-3 were partitioned separately with $\mathrm{GTR}+\mathrm{I}+\mathrm{G}, \mathrm{GTR}+\mathrm{I}+\mathrm{G}$, and $\mathrm{GTR}+\mathrm{G}$ site models, respectively; ingroup taxa were constrained to be monophyletic; Markov chain Monte Carlo (MCMC) for 200 million generations; samplefreq $=1,000$; and nruns $=2$. Convergence was assessed by observation of average split frequencies values below $\mathrm{p}<0.004$. A $50 \%$ Bayesian consensus tree was generated combining both runs using the sumt command with a $25 \%$ burn-in. We also performed an additional Bayesian analysis using BEAST2 ver. 2.6.2 (Bouckaert et al. 2019) with the following parameters: codon positions 1-3 were partitioned separately for site model averaging with the bModelTest package (Bouckaert \& Drummond 2017); a strict clock rate set to 1 for relative branch length estimation; Yule tree model; monophyletic constraint prior on ingroup taxa; MCMC for 200 million generations; and sampling trees and statistics every 1000 generations. After a $10 \%$ burn-in, effective sample size (ESS) for all parameters was determined to be greater than 200 with Tracer ver. 1.7.1 (Rambaut et al. 2018). A maximum clade credibility tree was estimated using TreeAnnotator ver. 2.6.0 (Bouckaert et al. 2019) with median node heights and a $10 \%$ burn-in. Maximum likelihood analysis was performed with RAxML-NG ver. 9.0 (Kozlov et al. 2019) using the all-in-one ML search and bootstrapping command (all), a partition file treating codon positions 1-3 as separate partitions with the same site models used for the MrBayes analysis, a constraint tree forcing monophyly for ingroup taxa, scaled branch lengths, and MRE-based bootstrapping (converged after 400 replicates). 
Table 1 (continued on next page). List of Entomobryinae species used for phylogenetic analysis, including locality and COI sequence information, i.e., GenBank accession number and sequence length (bp = base pairs). Abbreviations: $\mathrm{AH}=$ Anhui; $\mathrm{AL}=$ Alabama; $\mathrm{AM}=$ Amazonas; $\mathrm{AZ}=$ Azores; $\mathrm{BA}=$ Bahia; $\mathrm{BR}=$ Brazil; $\mathrm{CA}=$ Canada $\mathrm{CH}=$ China; $\mathrm{FL}=$ Florida; $\mathrm{FR}=$ France; $\mathrm{GD}=$ Guangdong; $\mathrm{HB}$ $=$ Hubei; $\mathrm{HN}=$ Hunan; IDF $=$ Île-de-France; $\mathrm{IL}=$ Illinois; $\mathrm{JL}=\mathrm{Jilin} ; \mathrm{NC}=$ North Carolina; $\mathrm{OOC}=$ Occitanie; $\mathrm{ON}=$ Ontario; $\mathrm{PA}=$ Pennsylvania; $\mathrm{PI}=$ Piauí; $\mathrm{PT}=$ Portugal TB $=$ Tibet $; \mathrm{TN}=$ Tennessee; $\mathrm{USA}=$ United States of America, $\mathrm{VT}=$ Vermont; WI $=$ Wisconsin; ZJ $=$ Zhejiang.

\begin{tabular}{|c|c|c|c|c|c|}
\hline & Species name & Locality & GenBank \# & bp & Reference \\
\hline 1 & Coecobrya tenebricosa & Antony, IDF, FR & KM978347 & 658 & Ding et al. 2018 \\
\hline 2 & Drepanura mogolica & Changling, JL, CH & KY468329 & 658 & Ding et al. 2018 \\
\hline 3 & Entomobrya assuta & Mason Co., IL, USA & KM610057 & 1534 & Katz et al. 2015a \\
\hline 4 & Entomobrya atrocincta & Champaign Co., IL, USA & KM610115 & 1534 & Katz et al. 2015a \\
\hline 5 & Entomobrya bicolor & Henderson Co., IL, USA & KM610117 & 1534 & Katz et al. 2015a \\
\hline 6 & Entomobrya citrensis & Citrus Co., FL, USA & KM610064 & 1534 & Katz et al. 2015a \\
\hline 7 & Entomobrya clitellaria & Coles Co., IL, USA & KM610076 & 1534 & Katz et al. 2015a \\
\hline 8 & Entomobrya decemfasciata & Stewart Co., TN, USA & KM610101 & 1534 & Katz et al. 2015a \\
\hline 9 & Entomobrya huangi & Nyingchi, TB, CH & KY468314 & 658 & Ding et al. 2018 \\
\hline 10 & Entomobrya intermedia & Chester Co., PA, USA & KM610121 & 1534 & Katz et al. 2015a \\
\hline 11 & Entomobrya jubata & Covington Co., AL, USA & KM610110 & 1534 & Katz et al. 2015a \\
\hline 12 & Entomobrya ligata & Swain Co., NC, USA & KM610079 & 1534 & Katz et al. 2015a \\
\hline 13 & Entomobrya multifasciata & São Miguel Island, AZ, PT & KM610123 & 1534 & Katz et al. 2015a \\
\hline 14 & Entomobrya neotenica & Clay Co., AL, USA & KM610104 & 1534 & Katz et al. 2015a \\
\hline 15 & Entomobrya nivalis & Lamoille Co., VT, USA & KM610125 & 1534 & Katz et al. 2015a \\
\hline 16 & Entomobrya quadrilineata & Vermilion Co., IL, USA & KM610092 & 1534 & Katz et al. 2015a \\
\hline 17 & Entomobrya unifasciata & Chester Co., PA, USA & KM610087 & 1534 & Katz et al. 2015a \\
\hline 18 & Entomobrya unostrigata & Champaign Co., IL, USA & MT454111 & 1530 & Katz et al. $2015 \mathrm{~b}$ \\
\hline 19 & Entomobryoides dissimilis & Champaign Co., IL, USA & KM610126 & 1534 & Katz et al. 2015a \\
\hline 20 & Homidia sauteri & Butler Co., AL, USA & KM610127 & 1501 & Katz et al. 2015a \\
\hline 21 & Homidia socia & Jo Davies Co., IL, USA & KM610128 & 1534 & Katz et al. 2015a \\
\hline 22 & Lepidocyrtoides caeruleomaculatus & Rio Preto da Eva, AM, BR & MF716618 & 1534 & Godeiro et al. 2020 \\
\hline 23 & Lepidocyrtoides sp. & Abaíra, BA, BR & MF716598 & 1534 & Godeiro et al. 2020 \\
\hline 24 & Lepidodens similis & Shaoguan, GD, CH & KM978396 & 658 & Ding et al. 2018 \\
\hline 25 & Lepidosira neotropicalis & Piracuruca, PI, BR & MF716603 & 1534 & Nunes et al. 2019 \\
\hline 26 & Sinhomidia bicolor & Huangshan, $\mathrm{AH}, \mathrm{CH}$ & KM978375 & 658 & Ding et al. 2018 \\
\hline 27 & Willowsia buski & Sauk Co., WI, USA & KM610129 & 1534 & Katz et al. 2015a \\
\hline 28 & Willowsia fascia & Huanggang, HB, CH & KU833222 & 658 & Ding et al. 2018 \\
\hline 29 & Willowsia guangdongensis & Guangzhou, GD, CH & KM978377 & 658 & Ding et al. 2018 \\
\hline 30 & Willowsia japonica & Linhai, ZJ, CH & KM978378 & 658 & Ding et al. 2018 \\
\hline 35 & Willowsia neonigromaculata sp. nov. & Pope Co., IL, USA & KM610130 & 1534 & Katz et al. 2015a \\
\hline 36 & Willowsia neonigromaculata sp. nov. & Brockville, ON, CA & MG034057 & 542 & deWaard et al. 2019 \\
\hline 31 & Willowsia nigromaculata & Teillet, OCC, FR & KY468311 & 658 & Ding et al. 2018 \\
\hline 32 & Willowsia nigromaculata & Toronto, ON, CA & MG032239 & 474 & deWaard et al. 2019 \\
\hline 33 & Willowsia nigromaculata & Toronto, ON, CA & MG036766 & 594 & deWaard et al. 2019 \\
\hline 34 & Willowsia nigromaculata & Toronto, ON, CA & MG039377 & 543 & deWaard et al. 2019 \\
\hline 37 & Willowsia pseudobuski & Lu'an, $\mathrm{AH}, \mathrm{CH}$ & KU833223 & 658 & Ding et al. 2018 \\
\hline
\end{tabular}


Table 1 (continued).

\begin{tabular}{llllll}
\hline & Species name & Locality & GenBank \# & bp & Reference \\
\hline 38 & Willowsia pyrrhopygia & Citrus Co., FL, USA & KM610131 & 1534 & Katz et al. 2015a \\
39 & Willowsia qui & Huangshan, AH, CH & KU833221 & 658 & Ding et al. 2018 \\
40 & Willowsia similis & Changsha, HN, CH & KU833225 & 658 & Ding et al. 2018 \\
\hline
\end{tabular}

\section{Results}

\section{Taxonomic descriptions}

The following characters are shared by both Willowsia species (described below) and are not repeated in the descriptions: scales apically pointed with long basal ribs covering $2 / 3$ of scale and present dorsally on head, thorax and abdomen (Figs 2-3A, 8); antenna, ventral head, legs, collophore and furcula unscaled (Figs 3D, 4, 7); mac heavily ciliate, apically truncate or acuminate (Fig. 1); mic basally smooth with longer ramificate ribs from distal half (Figs 1,3B); bothriotricha accessory chaeta with short ramificate ribs distally (Figs 1, 3C, 6D-F); antenna less than the trunk length (Figs 2, 8); Ant III distally with 2 apical organ somewhat elongated, 3 spiny guard sensilla, s-blunt sens of different sizes and ciliate chaetae (Fig. 5A); eyes 8+8, A and B larger, G and $\mathrm{H}$ smaller (Figs 5B, 9A); clypeal formula with 4 (112), 7 (f), 3 (pf0-1) ciliate chaetae, 11-2 and pf1 larger, 4 frontal chaetae smaller, others subequal; four prelabral chaetae ciliate; labral formula with 4 (a1-2), 5 (m0-2), 5 (p0-2) smooth chaetae, p0-1 larger, others subequal (Fig. 5C); four labral papillae apically pointed and subequal (Fig. 5D); labial palp with 5 main (A-E) and 1 hypostomal papilla (H), with 0, 5, 0, 4, 4, 2 guard appendages, respectively, l.p. of papilla E gently pointed and exceeds base of apical appendage (Fig. 5F); labium with 5 smooth proximal chaetae; basomedian and basolateral labial fields with a1-5 smooth, M, R (smaller), E, L1-2 ciliate (Fig. 5G); Th II-Abd V with ms and sens formula 1, 0|1,0,1,0,0 and 2, 2|1,2,2,+,3, respectively; Abd II-IV bothriotricha formula 2 (a5 and $\mathrm{m} 2$ ), 3 (a5, m2, and $\mathrm{m} 5$ ), and 2 (T2 and T4), respectively (Fig. 6); Tibiotarsus I-III sometimes subdivided on distal two thirds; tibiotarsus III distally with 1 inner smooth chaeta and 1 outer tenent hairs capitate and heavily ciliate (Figs 3D-E, 7E); pretarsus with 1 minute smooth chaeta on anterior and posterior sides (Figs 3D, 7E); unguis inner side with 4 inner teeth, b.t. paired and of same length than m.t., a.t. smaller; outer side with 2 paired basolateral teeth and 1 unpaired basomedian tooth, all with one lamella which extends to the base; unguiculus with four lamellae, ae, ai and pi acuminate and smooth, and pe serrated (Figs 3D-E, 7E); Mucro bidentate, proximal tooth gently smaller than distal, basal spine reaches apex of proximal tooth (Figs 3F, 7J).

Family Entomobryidae Schäffer, 1896

Subfamily Entomobryinae Schäffer, 1896 sensu Zhang \& Deharveng 2015

Genus Willowsia Shoebotham, 1917

Willowsia nigromaculata (Lubbock, 1873)

Figs 2-7, 10-11; Tables 2-3

Seira nigromaculata Lubbock 1873: 146, Great Britain (orig. descr.).

Willowsia nigromaculata - Shoebotham 1917: 432 (comb.). — Zhang et al. 2011 (descr.).

\section{Type species}

Seira nigromaculata Lubbock, 1873. 


\section{Diagnosis}

Body with pigments laterally on head to Abd III, and spots on Abd IV, femur and tibiotarsus (Fig. 2); head mac S0 absent, Ps3 mes and Ps5 mac present; sublobal plate with 2 inner appendages (Fig. 5E); Th II-Abd IV formula with 9,8|3,3,3+7,7+14 mac, p2a rarely present on Th III (Fig. 6A-C); manubrium dorsally with 7 lateral chaetae abruptly acuminate at the tip, manubrial plate with 3-4 chaetae, 1 mac (Fig. 7G-H).

\section{Material examined}

FRANCE $-2 \widehat{\jmath}, 5$ 우, 1 juvenile on slides, 7 specimens in alcohol; Paris, National Museum of Natural History, Department de Systematique et Évolution; 48 50'30.0" N, 02²1'33.1" E; in laboratory benchtop; 1 Jun. 2016; VD Tarli leg.; INPA.

\section{Description}

Length. Total length (head + trunk) of specimens $1.51-1.85 \mathrm{~mm}(\mathrm{n}=3)$. Specimens pale yellowish white with violet pigments on Ant II to Ant IV, head laterally, margins of Th II-Abd II, Abd III with one transverse band that expands laterally, Abd IV dorsally with one irregular lateral spot, irregular spots on
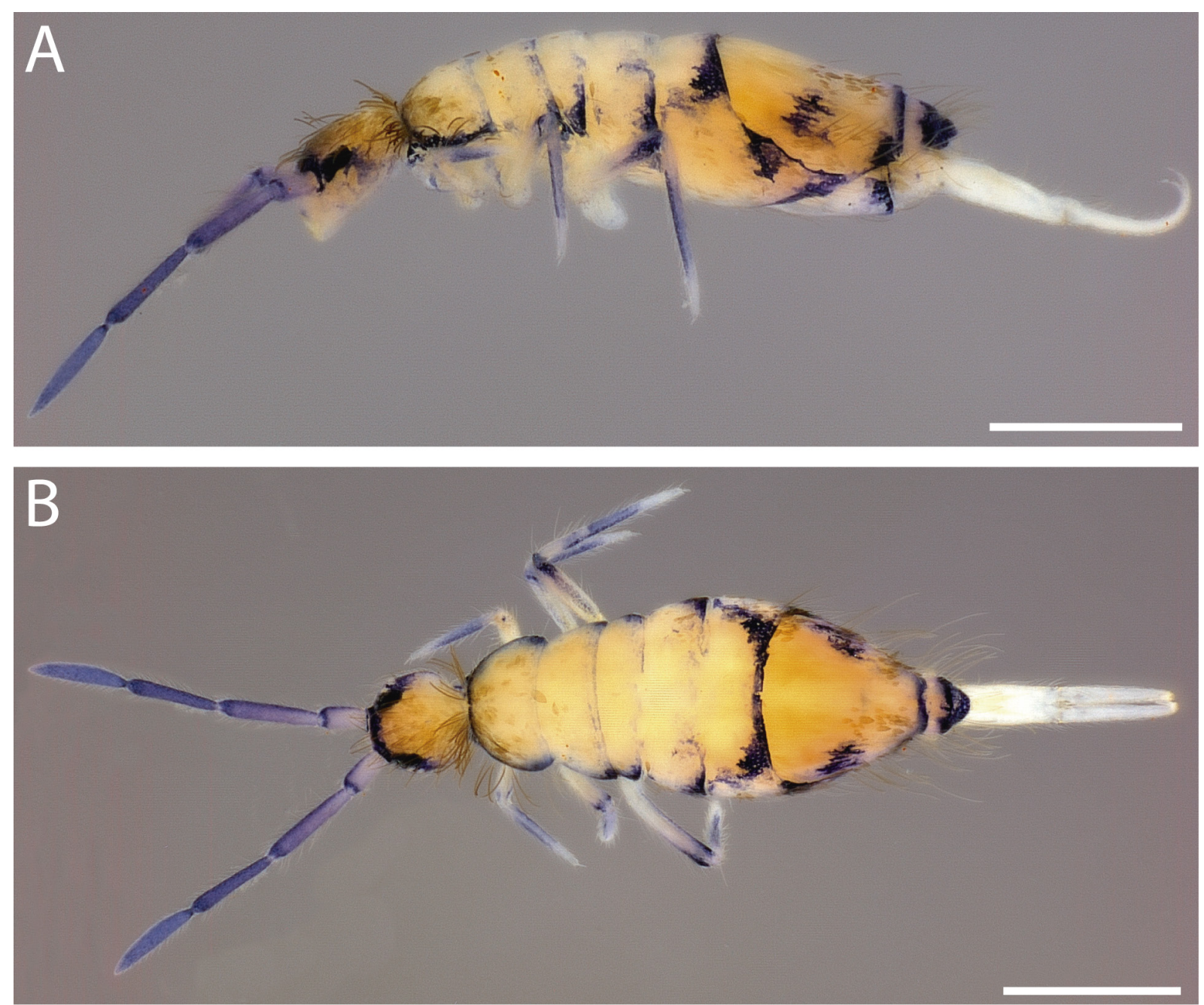

Fig. 2. Willowsia nigromaculata (Lubbock, 1873), habitus. A. Lateral view. B. Dorsal view. Scale bars: $0.5 \mathrm{~mm}$. 

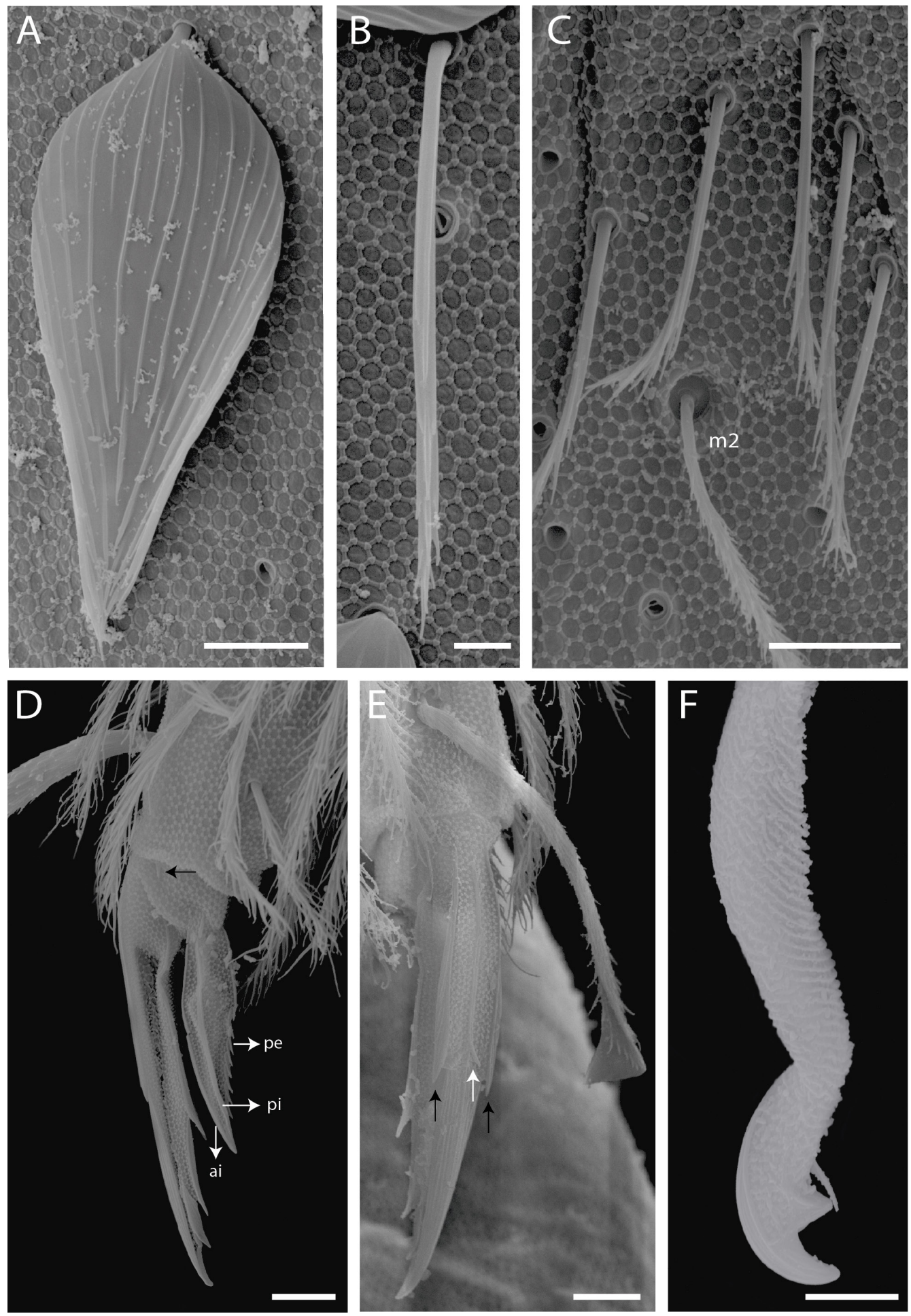

Fig. 3. Scanning electron microscopy of Willowsia nigromaculata (Lubbock, 1873). A. Scale apically pointed of Abd IV. B. Tergal microchaeta basally smooth and with ramification on distal half. C. Bothriotrichal complex of Abd II, $\mathrm{m} 2$ is bothriotrichum. D. Distal tibiotarsus and empodial complex I (posterior side), black arrow indicates pretarsal chaeta and white arrows indicates unguiculus lamellae. E. Distal tibiotarsus and empodial complex II (outer side), white arrow indicates unpaired basomedian tooth and black arrows indicates paired basolateral teeth of the unguis. F. Distal dens and mucro (lateral side). Abbreviations: see Material and methods. Scale bars: $A, C-F=5 \mu \mathrm{m} ; \mathrm{B}=2 \mu \mathrm{m}$. 
dorsoventral plate and posterior border; distal half of Abd V to VI, distal femur and tibiotarsus medially; eyepatches black (Fig. 2).

HEAD. Antennal ratio as I: II: III: IV = 1: $1.83-2.00$ 1.68-2.12: 1.81-2.36 $(\mathrm{n}=3)$. Ant IV not annulated, with apical bulb bilobed and sometimes retraticle. Five interocular chaetae (q, v, p, r, t); head dorsal macrochaetotaxy (Fig. 5B) with 5 'An' (An1a-3), 4 'A' (A0, A2-3, A5), 3 'M' (M1-2, M4), 6 'S' (S26), 1 'Ps' (Ps5), 5 'Pa' (Pa1-5), 2 'Pm' (Pm1, Pm3), 5 'Pp' (Pp1-5), and 2 'Pe' (Pe2-3) mac; An2a?, A1, A4? mic present. Maxillary palp with t.a. smooth and b.c. weakly striated, thicker and 1.12 longer than t.a.; sublobal plate with 2 inner (sb.2-3) and 1 outer (sb.4) smooth appendages, sb.2 smaller and sb.4 minute (Fig. 5E). Ventral chaetotaxy with about 68 ciliate chaetae, 36 thin of differents sizes, 31 normal and subequal in length and 1 b.c., cephalic groove with 6 chaetae; postlabial formula with 4 (G1-4), 4 (X, X2-4), 4 (H2-4), 4 (J1-4), 2 (X', X4') chaetae (Fig. 5G).

THORAX CHAETOTAXY (Fig. 6A). Th II, anterior collar with numerous chaetae; a, $\mathrm{m}$ and $\mathrm{p}$ series with 1 (a5), 1 (m4) and 7 (p1-5) mac, respectively. Th III, a, m and p series with 2 (a4, a6), 4 (m5-7) and 5-6 (p1-3, p5-6) mac, respectively, p2a mac rarely present; laterally numerous mes. Ratio Th II: III = 1.48-1.30: $1(\mathrm{n}=3)$.
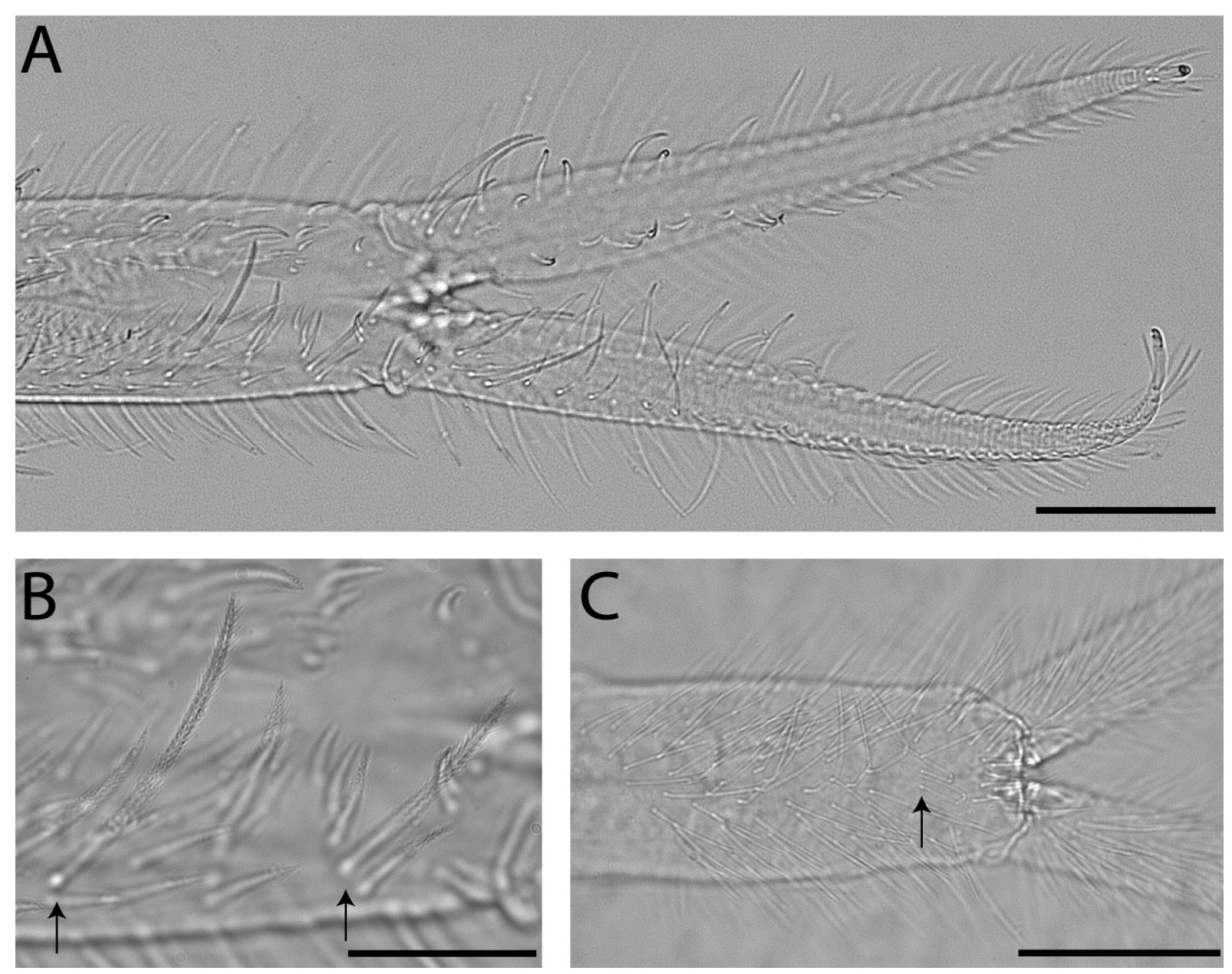

Fig. 4. Optical microscope photography of Willowsia nigromaculata (Lubbock, 1873). A. Furcula (dorsal view). B. Manubrium (dorsal view), arrows indicate mac and mes suddenly acuminate, respectively. C. Manubrium and proximal dentes (ventral view), arrow indicate subapical chaetae. Scale bars: $\mathrm{A}, \mathrm{C}=100 \mu \mathrm{m} ; \mathrm{B}=50 \mu \mathrm{m}$. 

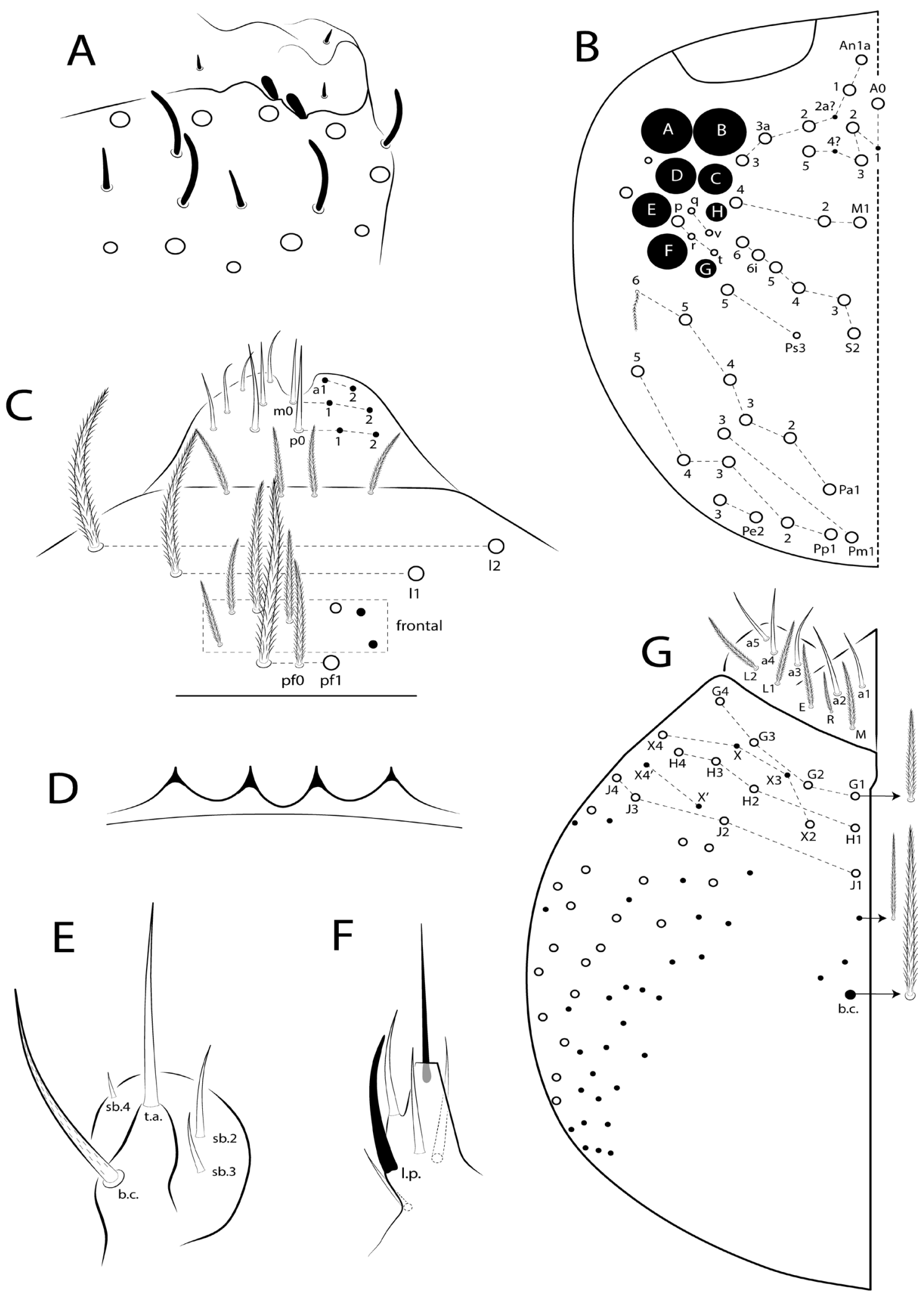

Fig. 5. Willowsia nigromaculata (Lubbock, 1873), head (left side). A. Ant III apical organ. B. Cephalic dorsal chaetotaxy. C. Chaetotaxy of clypeus, prelabrum and labrum. D. Labral papillae. E. Maxillary outer lobe. F. Papilla E of labial palp (ventral view). G. Basomedian and basolateral labial fields and complete postlabial chaetotaxy. Abbreviations: see Material and methods. 

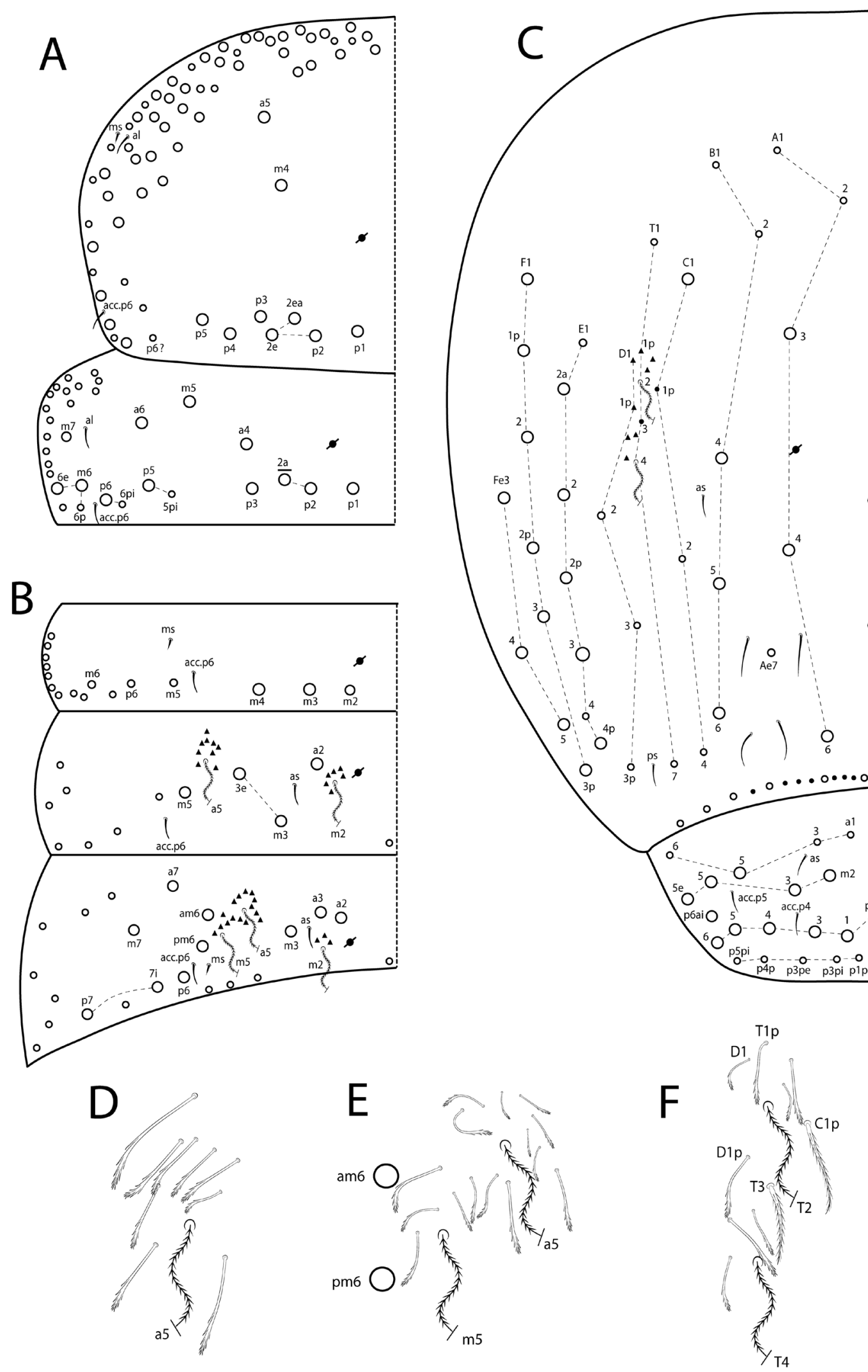

Fig. 6. Willowsia nigromaculata (Lubbock, 1873), dorsal chaetotaxy (left side). A. Th II-III. B. Abd I-III. C. Abd IV-V. D-F. Bothriotrichal complex. D. Abd II. E. Abd III. F. Abd IV. Abbreviations: see Material and methods. 

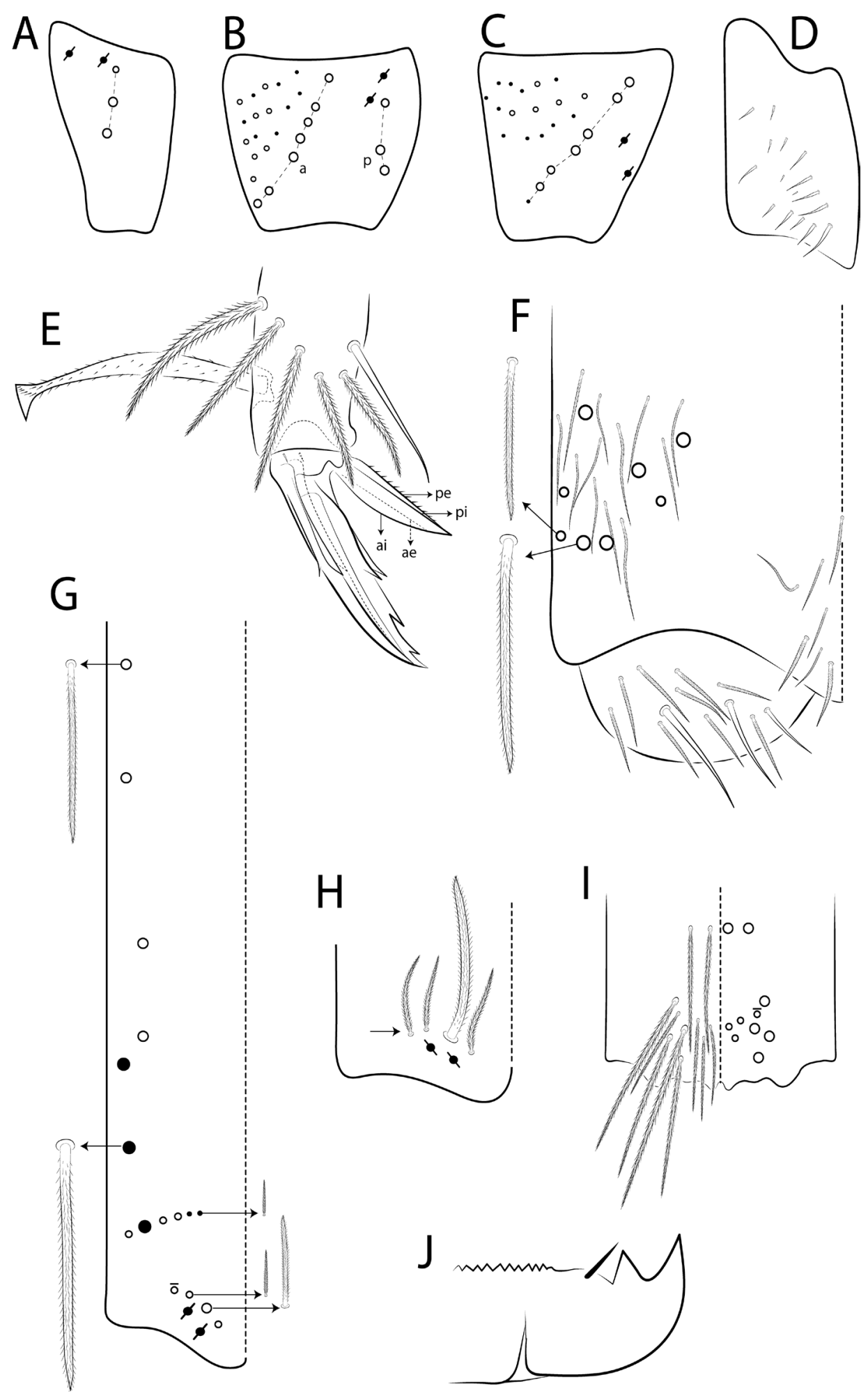

Fig. 7. Willowsia nigromaculata (Lubbock, 1873). A. Subcoxa I. B. Subcoxa II. C. Subcoxa III (lateral view). D. Trochanteral organ. E. Distal tibiotarsus and empodial complex III (posterior view). F. Collophore chaetotaxy (lateral view). G. Manubrium dorsal chaetotaxy. H. Manubrial plate. I. Subapical and apical chaetotaxy of ventral manubrium. J. Mucro (lateral view). Abbreviations: see Material and methods. 
Abdomen chaetotaxy (Fig. 6B-F). Abd I, m series with 3 mac (m2-4) subequal in length. Abd II, a and $\mathrm{m}$ series with 1 (a2) and 3 (m3-3e, m5) mac, respectively; a5 and $\mathrm{m} 2$ bothriotricha with 9 and 6 accessory chaetae, respectively (Figs 3C, 6D). Abd III, a, m and p series with 3 (a2-3, a7), 4 (m3, am6, pm6, m7) and 3 (p6, p7-7i) mac, respectively; m2 bothriotrichum with 3 accessory chaetae and a5 and $\mathrm{m} 5$ bothriotricha with 15 accessory chaetae between them (Fig. 6E). Abd IV, A to T series with 7 mac (A3-4, A6, B4-6, C1) and E to Fe series with 14 mac (E2a-3, E4p, F1-3p, Fe3-5); T2 and T4 bothriotricha with 2 mic and 8 accessory chaetae between them (Fig. 6F); 2 sens type I (as, ps), 4 sens type II, and 13 posterior chaetae of different sizes. Abd V a, m, pa and p series with 1 (a5), 4 (m2-3, m5-5e), 1 (p6ai) and 5 (p1, p3-6) mac, respectively. Ratio Abd III: IV =1: 3.61-4.14 (n=3).

Legs. Subcoxa I with 3 chaetae and 2 psp; subcoxa II with an anterior row of 7 chaetae and about 16 anterior chaetae, posterior row of 3 chaetae and 2 psp; subcoxa III with one row of 7 chaetae, about 16 anterior chaetae and 2 posterior psp (Fig. 7A-C). Trochanteral organ with 12-16 spine-like chaetae (Fig. 7D). Ratio unguis: unguiculus $=1: 0.52$. Tibiotarsal smooth chaeta 1.09 the length of unguiculus; tenent hairs 0.97 the length of unguis.

Collophore. Anterior side with about 20 chaetae, 5 mac and 3 mes ciliate and abruptly acuminate at the tip, and 13 thin chaetae weakly ciliate; posterior side with 8 chaetae (1 unpaired) weakly ciliate and 2 distally thicker; lateral flap with 3 smooth chaetae and 9 chaetae weakly ciliate (Fig. 7F).

FurCula. Manubrium ventrally with 4 subapical chaetae of the same length and 14-16 apical chaetae, 6 inner chaetae smaller, others subequal (Figs 4C, 7I); dorsally with one lateral row of 7 ciliate chaetae abruptly acuminate at the tip, 3 mac and 4 mes (1 basal and 1 antero-subapical); manubrial plate with 3-4 ciliate chaetae of different sizes ( 1 mac abruptly acuminate at the tip) and 2 psp (Figs $4 \mathrm{~A}-\mathrm{B}, 7 \mathrm{G}-\mathrm{H})$.

\section{DNA Barcodes}

GenBank KY468311; Teillet, France (Ding et al. 2018). GenBank MG032239, MG036766, MG039377; Toronto, Canada (deWaard et al. 2019).

Willowsia neonigromaculata sp. nov. Katz \& Cipola urn:1sid:zoobank.org:act:195E3CC7-B9AB-4CE9-93DE-BBA8ABA443C9

Figs 8-11; Tables 2-3

Willowsia nigromaculata - Katz 2015a: 829, Illinois, USA (phylogeny). - Katz 2015b: 64, Illinois, USA (phylogeny). — Katz 2017: 553, Illinois, USA (descr.). — deWaard et al. 2019: suppl. data, Brockville, Canada (DNA barcode, GenBank MG034057).

\section{Diagnosis}

Body with pigments laterally on head to Abd III, and spots on Abd IV, femur and tibiotarsus (Fig. 8), sometimes with piment covering nearly all Abd II-III medially and posterior half of Abd IV; head mac S0 present or absent, Ps3 mes and Ps5 mac absent (Fig. 9A); sublobal plate with 3 inner appendages (Fig. 9B); Th II-Abd IV formula with 9,8|3,3,3+7,7+14 mac, p2a present on Th III; manubrium dorsally with 9 lateral chaetae abruptly acuminate at the tip, manubrial plate with 4 chaetae, 2 mac (Fig. 9E).

\section{Etymology}

The specific epithet is derived from the Greek adjective 'vÉos, $-\alpha$, -ov', Latinized 'neos, - $a,-u m$ ' (combining form neo-), 'new, recent, young' + the epithet of the species Willowsia nigromaculata 

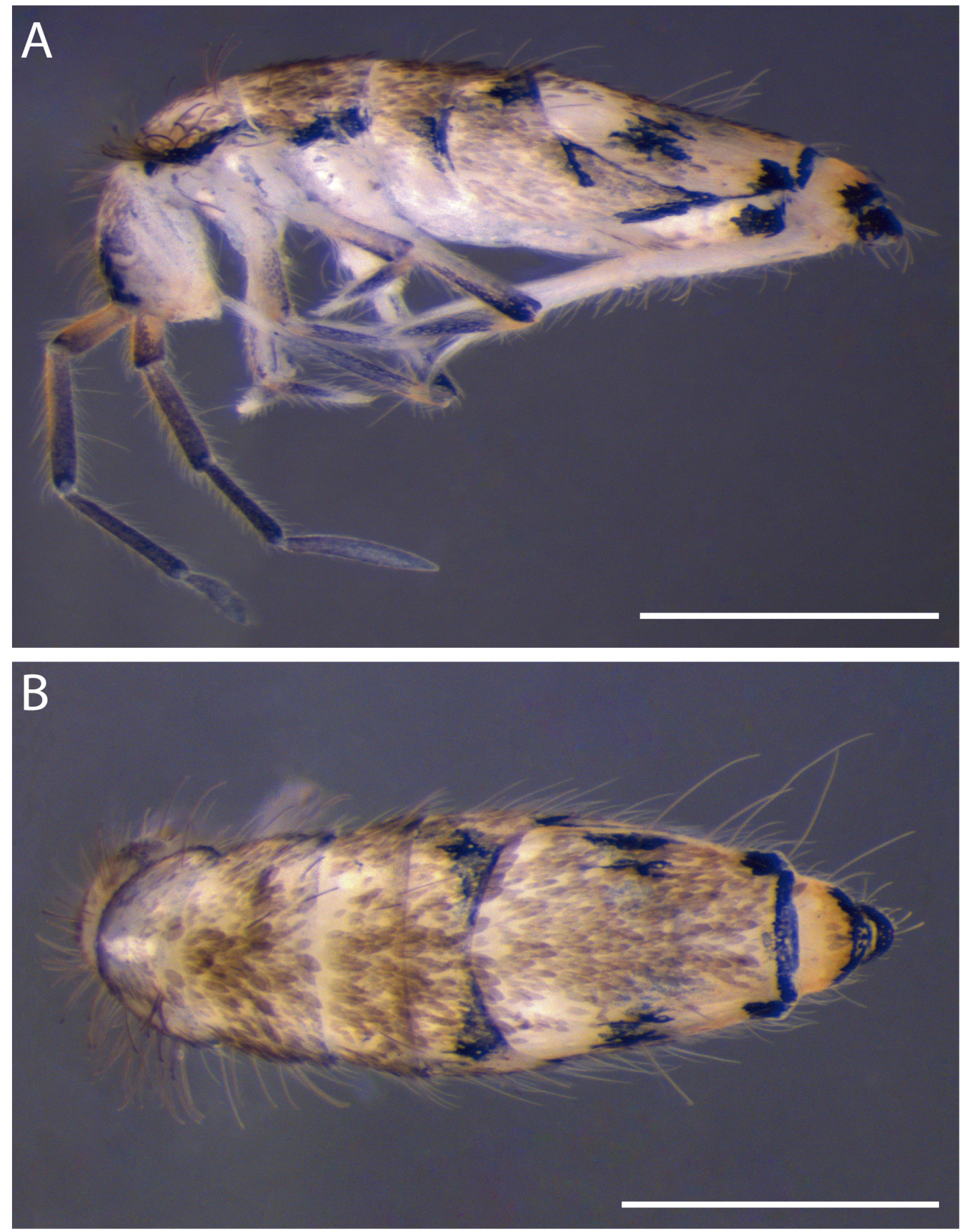

Fig. 8. Willowsia neonigromaculata sp. nov., paratype, $q$ (INHS 810158), habitus. A. Lateral view. B. Dorsal view. Scale bars: $0.5 \mathrm{~mm}$. 

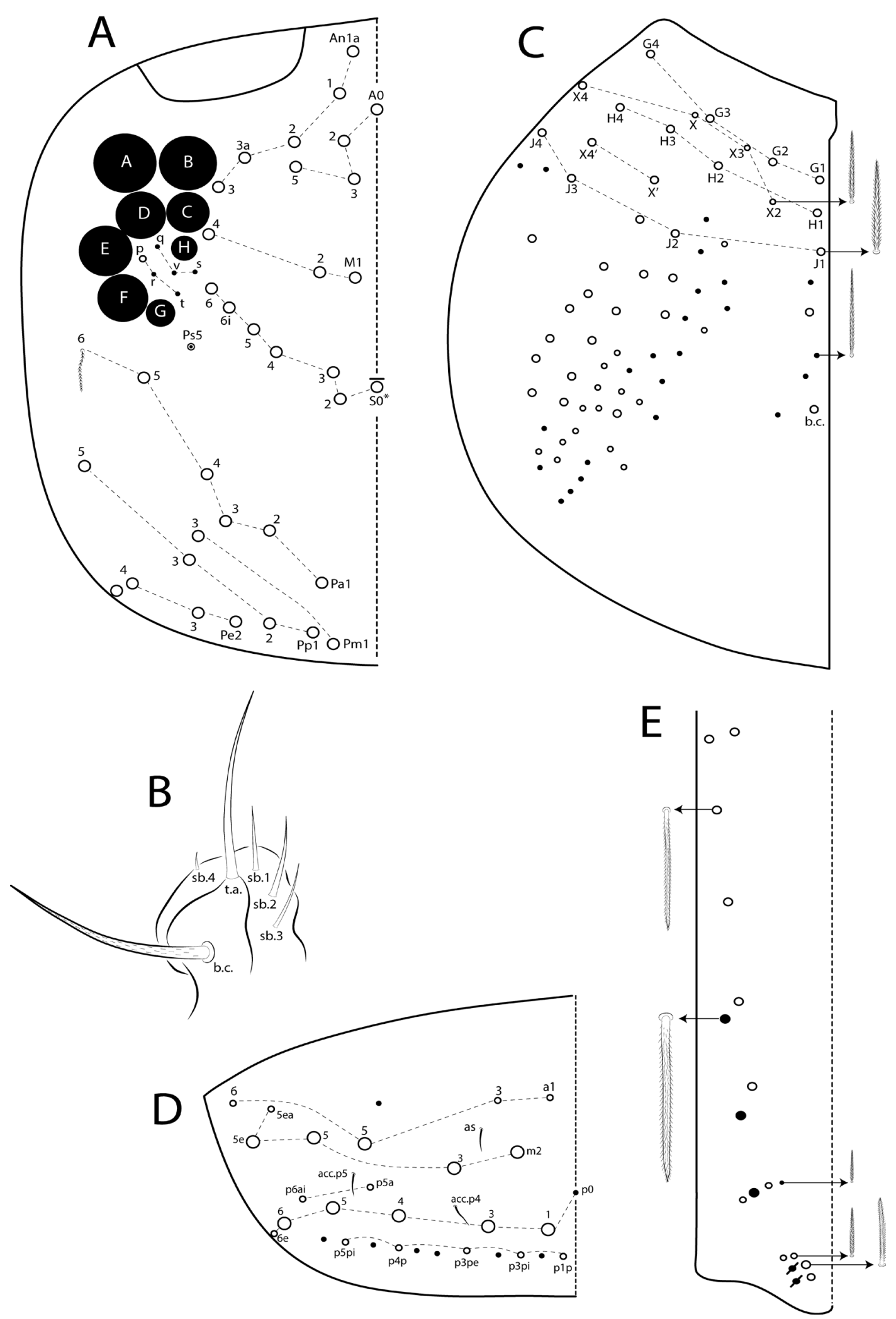

Fig. 9. Willowsia neonigromaculata sp. nov., body parts (left side). A. Cephalic dorsal chaetotaxy. B. Maxillary outer lobe. C. Complete postlabial chaetotaxy. D. Abd V dorsal chaetotaxy. E. Manubrium dorsal chaetotaxy. Abbreviations: see Material and methods. 
(Lubbock, 1873). The name references the new species' morphological affinity with $W$. nigromaculata and its presence in the New World.

\section{Material examined}

\section{Holotype}

USA - 1 \& on slide; Illinois, Pope Co., Dixon Springs Agricultural Center; 37²6 $03.65^{\prime \prime}$ N, 88 40'01.84" W; altitude $524 \mathrm{~m}$, hand collected on pavement on dying Arilus cristatus; 23 Sep. 2011; A. Katz leg.; adk11-159; INHS 810161.

\section{Paratypes}

USA 1 $1 \hat{\partial}, 2$ +, 2 undetermined sex on slides and 30 specimens in alcohol; same data as for holotype; INHS 810157-810160, INHS 810162, INHS 810163.

\section{Other material}

USA • 1 undetermined sex on slide; Illinois, Urbana, 19 Montclair Rd; $40^{\circ} 05^{\prime} 41.5^{\prime \prime} \mathrm{N}, 88^{\circ} 12^{\prime} 24.7^{\prime \prime} \mathrm{W}$; 6 Jul. 2008; by kitchen sink; F Soto-Adames leg.; INHS 810,164 2 q $q$ on slide; same collection data as for preceding, except 2012 (no specific date); INHS 810165.

\section{Description}

LENGTH. Total length (head + trunk) of specimens $1.51-1.85 \mathrm{~mm}(\mathrm{n}=3)$. Specimens pale yellowish white with violet pigments on distal half of the Ant I to Ant IV, head laterally, margins of Th II-Abd II, Abd III with one transverse band that expands laterally, Abd IV dorsally with one irregular lateral spot and one weak central spot, irregular spots on dorsoventral plate and posterior margin; distal half of Abd V to VI, distal femur and tibiotarsus medially; eyepatches black (Fig. 8). Sometimes depigmented on proximal part of the Ant II; pigments on posterior one third of the Th II and Abd I, almost all Abd II-III medially, and posterior half of Abd IV (see Katz 2017: 551).

HEAD. Antennal ratio as I: II: III: IV =1: 1.83-2.00: 1.68-2.12:1.81-2.36 $(\mathrm{n}=3)$. Ant IV not annulated, with apical bulb simple or bilobed, rarely retracted. Six interocular chaetae (q, v, s, p, r, t); head dorsal macrochaetotaxy (Fig. 9A) with 5 'An' (An1a-3), 4 'A' (A0, A2-3, A5), 3 'M' (M1-2, M4), 6-7 'S' (S0, S2-6), 0 'Ps', 5 'Pa' (Pa1-5), 2 'Pm' (Pm1, Pm3), 4 'Pp' (Pp1-3, Pp5), and 4 'Pe' (Pe2-3 plus 1 unnamed) mac; An2a?, A1, A4? mic absent. Maxillary palp with t.a. smooth and b.c. weakly striated, thicker and 1.10 longer than t.a.; sublobal plate with 3 inner (sb.1-3) and 1 outer (sb.4) smooth appendages, sb.1 gently smaller, sb.3 thin, and sb.4 minute (Fig. 9B). Ventral chaetotaxy with about 74 ciliate chaetae, 23 thin, 18 slightly smaller, and 33 normal and subequal in length (including b.c.), cephalic groove with 8 chaetae; postlabial formula with 4 (G1-4), 4 (X, X2-4), 4 (H2-4), 4 (J1-4), 2 (X', X4') chaetae (Fig. 9C).

Thorax CHAetotaxy (as Fig. 6A). Th II and III similar to W. nigromaculata, except Th III p2a mac always present. Ratio Th II: III = 1.48-1.30: $1(\mathrm{n}=3)$, holotype 1.30: 1 .

ABdomen CHAETOTAXY (as Figs 6B-F and 9D). Abd I to IV similar to W. nigromaculata, except Abd I m2 smaller in length and socket size, Abd II a5 and $\mathrm{m} 2$ bothriotricha with 8-9 and 6 accessory chaetae, Abd III $\mathrm{m} 2$ bothriotrichum with 3-4 accessory chaetae and a5 and $\mathrm{m} 5$ bothriotricha with $12-15$ accessory chaetae between them, and Abd IV T2 and T4 bothriotricha with 2 mic and 8-11 accessory chaetae between them. Abd V a, m and p series with 1 (a5), 4 (m2-3, m5-5e), and 5 (p1, p3-6) mac, respectively (Fig. 9D). Ratio Abd III: IV = 1: 3.61-4.14 ( $\mathrm{n}=3)$, holotype 1: 3.80 .

Chattotaxy of the legs and collophore. Similar to W. nigromaculata (Fig. 7A-F). 
FURCULA. Manubrium ventrally similar to W. nigromaculata (as Figs 4C, 7I); dorsally with one lateral row of 9 ciliate chaetae abruptly acuminate at the tip, 3 mac and 6 mes ( 2 basal and 2 antero-subapical); manubrial plate with 4 ciliate chaetae of different sizes ( 2 mac abruptly acuminate at the tip) and 2 psp (Fig. 9E).

\section{DNA Barcodes}

GenBank KM610130; collection locality information same as holotype (Katz et al. 2015a). GenBank MG034057; Brockville, Canada (deWaard et al. 2019).

\section{Remarks}

Willowsia neonigromaculata sp. nov. is considered a new species that is distinct from W. nigromaculata, supported by both morphological (Table 2) and molecular evidence (Table 3, Figs 10-11). Willowsia neonigromaculata sp. nov. resembles $W$. nigromaculata in most morphological characteristics, but differs in head by cephalic mac Ps5 and Pp4 absent and Pe4 plus one extra mac present (opposite in W. nigromaculata), 3 mic (An2a?, A1, A4?) absent (present in W. nigromaculata) and interocular $\mathrm{s}$ chaetae present (absent in $W$. nigromaculata), sublobal plate with 3 inner appendages $(2$ in $W$. nigromaculata), and ventral groove with 8 chaetae (6 in W. nigromaculata). On Abd I, $\mathrm{m} 2$ mac for Willowsia neonigromaculata sp. nov. smaller in length and socket size than $\mathrm{m} 3$ and $\mathrm{m} 4$ (normal in W. nigromaculata), and Abd V with 3 chaetae (m5ea, p5a, p6e), all absent in W. nigromaculata. They also differ in manubrium dorsally with 2 basal and 2 antero-subapical chaetae abruptly acuminate at the tip ( 1 basal and 1 antero-subapical in W. nigromaculata), and manubrial plate with 2 inner mac ( 1 in W. nigromaculata).

\section{Genetic analysis}

COI p-distances revealed remarkably high levels of genetic variation among specimens identified as W. nigromaculata, with p-distances ranging from $0 \%$ to $13.47 \%$ (Table 3). Moreover, there is a large gap in the distribution of genetic distances (0-1.18\% and 9-13.47\%, respectively) (Fig. 10), corresponding to the separation of two phylogenetically distinct lineages within $W$. nigromaculata (Fig. 11). Distances between these two clades (Fig. 10, line C) are similar to distances between other Entomobryinae species (Fig. 10, line A) and distances between Entomobryinae sister taxa (Fig. 10, line B).

Both Bayesian and maximum likelihood phylogenetic approaches produced mostly congruent gene tree topologies, with lineages of the W. nigromaculata forming two distinct clades with high support (Fig. 11): (1) a $W$. neonigromaculata sp. nov. clade that includes sequences representing $W$. neonigromaculata sp. nov. collected from Dixon Springs, Illinois, USA and Brockville, Canada (previously identified as $W$. nigromaculata); and (2) a W. nigromaculata clade that includes $W$. nigromaculata sequences from specimens collected in Teillet, France and Toronto, Canada. Phylogenetic divergence between these two clades is similar to that observed between other Entomobryinae sister species (Fig. 11).

\section{Discussion}

Cryptic species are thought to comprise a vast majority of springtail diversity (Porco et al. 2012; Cicconardi et al. 2013), which has contributed to the rise of studies that focus on integrating morphological and molecular data to delimit cryptic species within various groups of Collembola (e.g., Zhang et al. 2014c, 2018, 2019; Katz et al. 2015a; Sun et al. 2017; Skarżyński et al. 2018; Yu et al. 2018; Carapelli et al. 2020). Likewise, we provide both morphological and molecular evidence that lineages of Willowsia nigromaculata comprise at least two species - W. neonigromaculata sp. nov. in North America and W. nigromaculata in France and Canada, but also reported throughout the Holarctic realm. Morphological analysis revealed a number of subtle, yet significant differences in chaetotaxy between the two species (Table 2), including the number of inner appendages on the maxillary sublobal plate (Figs 5E, 9B) - a character thought to 
Table 2. Morphological comparison between Willowsia nigromaculata (Lubbock, 1873) and W. neonigromaculata sp. nov. ('+' is present; '-' is absent).

\begin{tabular}{|c|c|c|c|}
\hline & & & Species \\
\hline & & W. nigromaculata & W. neonigromaculata sp. nov. \\
\hline Character & & France & USA \\
\hline Cephalic dorsal & S0 & + & $+/-$ \\
\hline \multirow[t]{4}{*}{ macrochaetotaxy } & Ps5 & + & - \\
\hline & $\mathrm{Pp} 4$ & + & - \\
\hline & $\mathrm{Pe} 4$ & - & + \\
\hline & Pe extra & - & + \\
\hline Number of interocular chaetae & & 5 & 6 \\
\hline $\begin{array}{l}\text { Inner appendages on maxillary } \\
\text { sublobal plate }\end{array}$ & & 2 & 3 \\
\hline \multirow[t]{4}{*}{ Postlabial chaetotaxy } & $\mathrm{X}, \mathrm{X}^{\prime}$ & mic & mes \\
\hline & $\mathrm{X} 3, \mathrm{X} 4$ & mic & mes \\
\hline & groove & 6 & 8 \\
\hline & b.c. & larger & normal \\
\hline Th II-Abd IV mac formula & & $9,8 \mid 3,3,3+7,7+14$ & $9,8 \mid 3,3,3+7,7+14$ \\
\hline \multirow[t]{4}{*}{ Abd V chaetotaxy } & m5ea & - & + \\
\hline & $\mathrm{p} 5 \mathrm{a}$ & - & + \\
\hline & p6ai & mac & mes \\
\hline & p6e & - & + \\
\hline Manubrium ventral & basal & 1 & 2 \\
\hline \multirow[t]{2}{*}{ chaetotaxy } & antero-subapical & 2 & 1 \\
\hline & subapical & 6 & 4 \\
\hline \multirow[t]{2}{*}{ Manubrial plate } & number & $3-4$ & 4 \\
\hline & mac & 1 & 2 \\
\hline
\end{tabular}

be highly conserved across Entomobryinae (Katz 2017). The presence of only 2 inner appendages for $W$. nigromaculata from France is surprising, given that to date, only three other species of Entomobryinae are known to share this character state: Americabrya arida (Christiansen \& Bellinger, 1980), Willowsia mexicana Zhang, Palacios-Vargas \& Chen, 2007, and Willowsia pyrrhopygia Katz, 2017 - all of which are endemic to the New World (Katz 2017). However, until recently, this character was rarely reported in the literature, so it is possible that 2 inner appendages may be more common than previously thought.

The recovery of two highly supported and phylogenetically distinct clades (Fig. 11), separated by approximately $13 \%$ sequence divergence (Table 3; Fig. 10), provides additional support for our new species designation. However, the presence of both species in Canada indicates that the distribution of diversity in this group does not seem to correspond with geography. Extremely low levels of sequence divergence (approx. 1\%) observed between W. nigromaculata specimens collected in France and Toronto, Canada (Table 3) are indicative of a recent range expansion via trans-Atlantic dispersal, possibly facilitated by W. nigromaculata's strong association with human structures. As expected, the phylogenetic analysis also supports previous observations of para-/polyphyletic genera within Entomobryinae (Zhang et al. 2014a, 2014b, 2015, 2016, 2017; Katz et al. 2015b, 2017; Zhang \& 
Deharveng 2015; Ding et al. 2018), though the primary objective of this study was to assess genetic diversity within Willowsia, not to resolve generic relationships within Entomobryinae - a task that will likely require large, genomic data sets.

We consider the specimen identified as W. nigromaculata from Brockville, Ontario, Canada (deWaard et al. 2019), as a synonym of $W$. neonigromaculata sp. nov. based on genetic similarity $(0.18 \%$ COI sequence divergence). Sequence divergence in COI seems to accumulate long before obvious morphological divergence in springtails, with cryptic species often having $>8 \%$ sequence divergence in COI (Porco et al. 2012; Cicconardi et al. 2013; Katz et al. 2015a). Nevertheless, future morphological analysis of Canadian specimens would provide additional support for the presence of $W$. neonigromaculata sp. nov. in Canada.

In light of these results, we expect that specimens previously identified as $W$. nigromaculata, especially those collected in the USA and Canada, may actually be W. neonigromaculata sp. nov. and the reexamination of old material may reveal additional new species. Additional morphological and molecular investigations of specimens collected throughout the Holarctic region are needed to better understand the diversity and distribution of W. nigromaculata and W. neonigromaculata sp. nov.

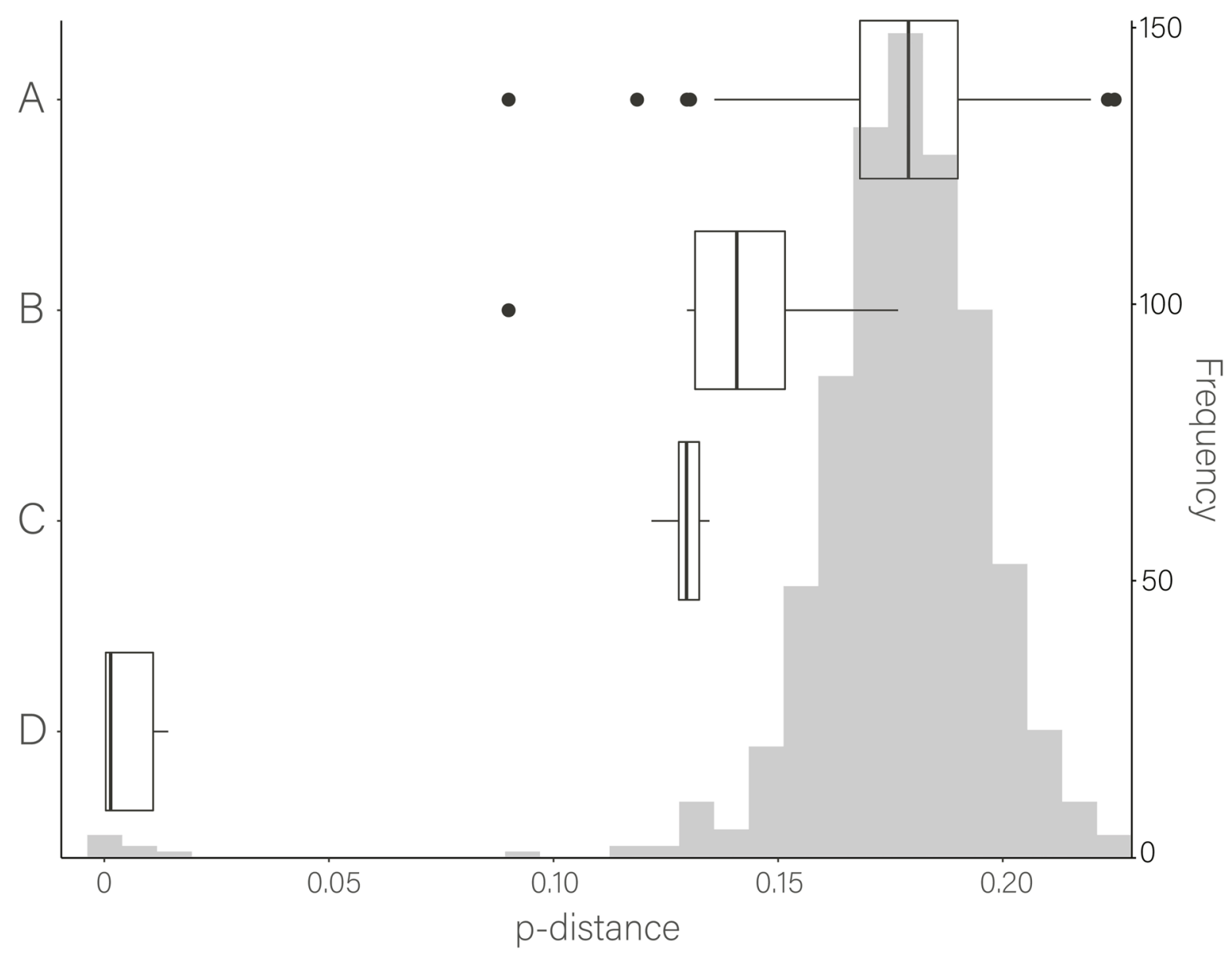

Fig. 10. COI p-distance (uncorrected) frequency histogram (in gray) and boxplots comparing p-distances between A. Entomobryinae species. B. Entomobryinae sister species. C. Willowsia nigromaculata (Lubbock, 1873) (France and Toronto, Canada) and W. neonigromaculata sp. nov (USA and Brockville, Canada) clades (inter-specific distances). D. Lineages within the same $W$. nigromaculata or W. neonigromaculata sp. nov. clade (intra-specific distances). 
CIPOLA N.G. \& KATZ A.D., Willowsia nigromaculata and W. neonigromaculata sp. nov. from the USA

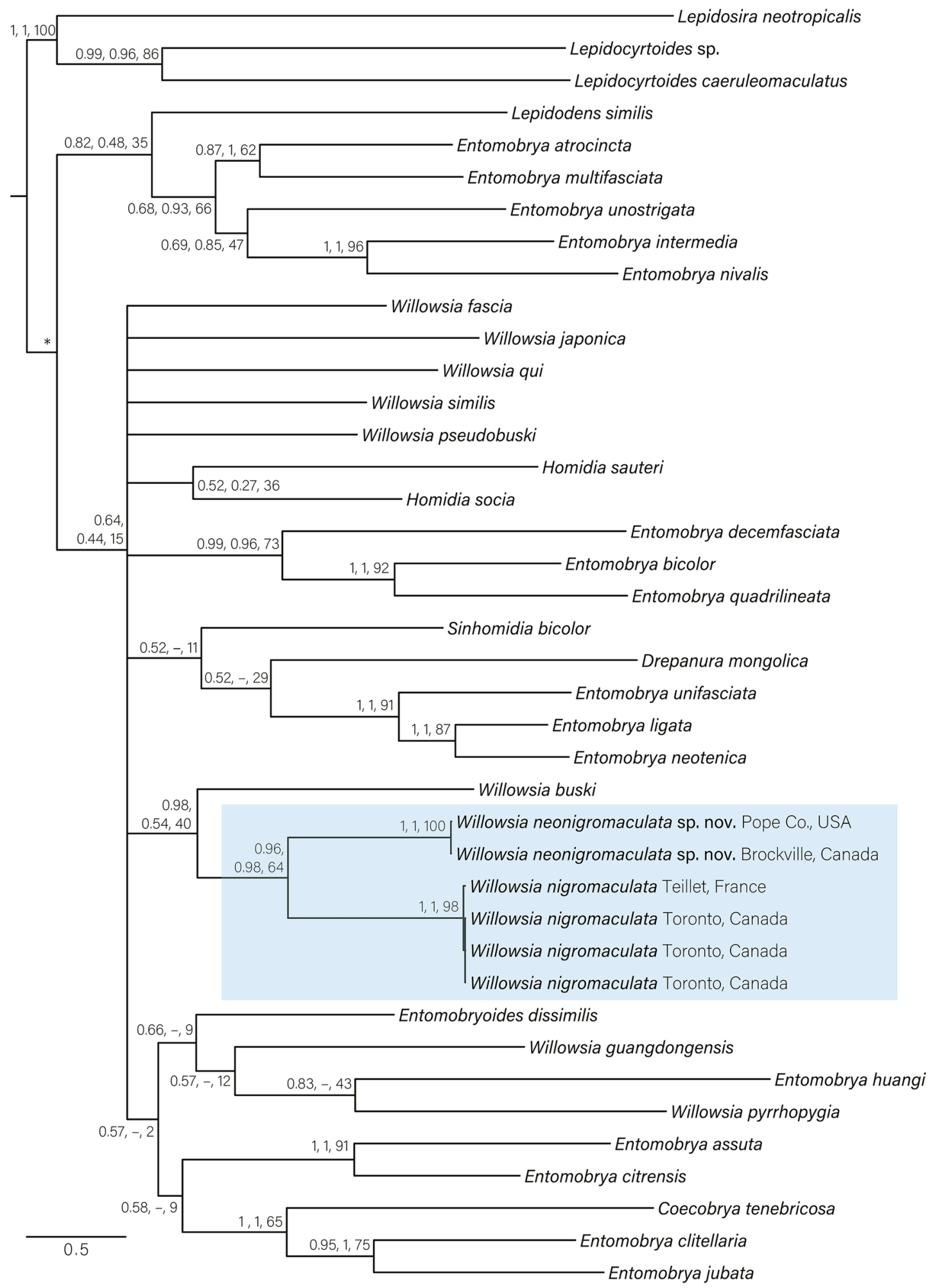

Fig.11. Bayesian consensus tree estimated with MrBayes forEntomobryinae, including the clade comprised of Willowsia nigromaculata (Lubbock, 1873) from France and Canada and W. neonigromaculata sp. nov. from the USA and Canada (highlighted). MrBayes and BEAST posterior probabilities and RAxML bootstraps are indicated at each node, respectively. The ingroup node constrained as monophyletic for all phylogenetic analyses is indicated with an asterisk (*). 
Table 3. COI p-distances between Willowsia nigromaculata (Lubbock, 1873) and W. neonigromaculata sp. nov. References: Katz et al. 2015a ${ }^{1}$; Ding et al. 2018²; deWaard et al. 2019³. Abbreviations: CA = Canada; FR = France.

\begin{tabular}{|c|c|c|c|c|c|c|c|}
\hline & & & & & Willowsia & & \\
\hline Species name & Locality & $\begin{array}{c}\text { COI } \\
\text { GenBank } \\
\text { accession \# }\end{array}$ & $\begin{array}{c}\text { neonigromacula- } \\
\text { ta sp. nov. USA } \\
\text { KM610130 }\end{array}$ & $\begin{array}{l}\text { nigromacu- } \\
\text { lata France } \\
\text { KY468311 }\end{array}$ & $\begin{array}{l}\text { nigromacu- } \\
\text { lata Toronto } \\
\text { MG032239 }\end{array}$ & $\begin{array}{l}\text { nigromacu- } \\
\text { lata Toronto } \\
\text { MG036766 }\end{array}$ & $\begin{array}{c}\text { nigromacu- } \\
\text { lata Toronto } \\
\text { MG039377 }\end{array}$ \\
\hline \multirow[t]{5}{*}{ W. nigromaculata } & $\begin{array}{l}\text { Tiellet, } \\
\text { FR }\end{array}$ & KY468311² & $12.92 \%$ & & & & \\
\hline & $\begin{array}{l}\text { Toronto, } \\
\text { CA }\end{array}$ & MG032239 & $12.05 \%$ & $1.06 \%$ & & & \\
\hline & $\begin{array}{l}\text { Toronto, } \\
\text { CA }\end{array}$ & MG036766 3 & $13.03 \%$ & $1.18 \%$ & $0.00 \%$ & & \\
\hline & $\begin{array}{l}\text { Toronto, } \\
\text { CA }\end{array}$ & MG039377³ & $13.10 \%$ & $1.11 \%$ & $0.00 \%$ & $0.00 \%$ & \\
\hline & $\begin{array}{l}\text { Brock- } \\
\text { ville, CA }\end{array}$ & $\mathrm{MG} 034057^{3}$ & $0.18 \%$ & $13.47 \%$ & $12.26 \%$ & $12.93 \%$ & $12.99 \%$ \\
\hline
\end{tabular}

\section{Acknowledgments}

We would like to thank Dr Vitor D. Tarli (MNHN) who supplied us the material described in this study, Dr Feng Zhang (Nanjing Agricultural University) for molecular data communication, CAPES Pro-Equipamentos (Dra Neusa Hamada/INPA), Laboratório de Sistemática e Ecologia de Invertebrados do Solo (Dra. Elizabeth F. Chilson/INPA) and Laboratório Temático de Microscopia Óptica e Eletrônica (LTMOE/ INPA, by J. Veras, L. Castanhola, and J.W. Meirelles) for logistic support with the images, and Daniel R. Swanson (University of Illinois at Urbana-Champaign) for his etymological expertise. The first author's post-doctoral appointment is granted by CNPq (PCI-DB, Process \# 300925/2019-0).

\section{References}

Bellinger P.F., Christiansen K.A. \& Janssens F. 2020. Checklist of the Collembola of the World. Available from http://www.collembola.org [accessed 20 Apr. 2020].

Bouckaert R. \& Drummond A. 2017. bModelTest: Bayesian phylogenetic site model averaging and model comparison. BMC Evolutionary Biology 17: 42. https://doi.org/10.1186/s12862-017-0890-6

Bouckaert R., Vaughan T.G., Barido-Sottani J., Duchêne S., Fourment M., Gavryushkina A., Heled J., Jones G., Kühnert D., De Maio N., Matschiner M., Mendes F.K., Müller N.F., Huw A. Ogilvie H.A., du Plessis L., Popinga A., Rambaut A., Rasmussen D., Siveroni I., Suchard M.A., Wu C.-H., Xie D., Zhang C., Stadler T. \& Drummond A.J. 2019. BEAST 2.5: An advanced software platform for Bayesian evolutionary analysis. PLoS Computational Biology 15 (4): e1006650.

https://doi.org/10.1371/journal.pcbi.1006650

Carapelli A., Greenslade P., Nardi F., Leo C., Convey P., Frati F. \& Fanciulli P.P. 2020. Evidence for the cryptic diversity in the "Pan-Antarctic" springtail Friesea antarctica and the description of two new species. Insects 11 (3): 141. https://doi.org/10.3390/insects11030141

Chen J.-X. \& Christiansen K.A. 1993. The genus Sinella with special reference to Sinella s. s. (Collembola: Entomobryidae) of China. Oriental Insects 27: 1-54. 
Christiansen K. \& Bellinger P. 1980. The Collembola of North America, North of the Rio Grande: A Taxonomic Analysis. Grinnell College, Grinnell, Iowa.

Christiansen K. \& Bellinger P. 1998. The Collembola of North America, North of the Rio Grande: A Taxonomic Analysis. Grinnell College, Grinnell, Iowa.

Cicconardi F., Fanciulli P.P. \& Emerson B.C. 2013. Collembola, the biological species concept and the underestimation of global species richness. Molecular Ecology 22 (21): 5382-5396.

https://doi.org/10.1111/mec.12472

Cipola N.G., Morais J.W. \& Bellini B.C. 2014. A new species of Seira (Collembola: Entomobryidae: Seirini) from Northern Brazil, with the addition of new chaetotaxic characters. Zoologia 31: 489-495. https://doi.org/10.1590/S1984-46702014000500009

Cipola N.G., Oliveira J.V.L.C., Bellini B.C., Ferreira A.S., Lima E.C.A., Brito R.A., Stievano L.C., Souza P.G. \& Zeppelini D. 2020. Review of eyeless Pseudosinella Schäffer (Collembola, Entomobryidae, Lepidocyrtinae) from Brazilian caves. Insects 11: 1-140. https://doi.org/10.3390/insects11030194

deWaard J.R., Ratnasingham S., Zakharov E.V., Borisenko A.V., Steinke D., Telfer A.C., Perez K.H.J., Sones J.E., Monica R. Young M.R., Valerie Levesque-Beaudin V., Crystal N. Sobel C.N., Abrahamyan A., Bessonov K., Blagoev G., deWaard S.L., Ho C., Ivanova N.V., Layton K.K.S., Lu L., Manjunath R., McKeown J.T.A., Milton M.A., Miskie R., Monkhouse N., Naik S., Nikolova N., Pentinsaari M., Prosser S.W.J., Radulovici A.E., Steinke C., Warne C.P. \& Hebert P.D.N. 2019. A reference library for Canadian invertebrates with 1.5 million barcodes, voucher specimens, and DNA samples. Scientific Data 6: 308. https://doi.org/10.1038/s41597-019-0320-2

Ding Y.-H., Yu D.-Y., Guo W.-B., Li J.-N. \& Zhang F. 2018. Molecular phylogeny of Entomobrya (Collembola: Entomobryidae) from China: Color pattern groups and multiple origins. Insect Science 26 (3): 587-597. https://doi.org/10.1111/1744-7917.12559

Fjellberg A. 1999. The Labial Palp in Collembola. Zoologischer Anzeiger 237: 309-330.

Fjellberg A. 2007. The Collembola of Fennoscandia and Denmark, Part II: Entomobryomorpha and Symphypleona. Fauna Entomologica Scandinavica Volume 42, Brill, Leiden.

Gisin H. 1960. Collembolenfauna Europas. Museum D'Histoire naturelle, Genève.

Gisin H. 1967. Espèces nouvelles et lignées évolutives de Pseudosinella endogés. Memórias e Estudos do Museu Zoológico da Universidade de Coimbra 301: 5-25.

Godeiro N.N., Pacheco G., Liu S., Cipola N.G., Berbel-Filho W.M., Zhang F., Gilbert M.T.P. \& Bellini B.C. 2020. Phylogeny of Neotropical Seirinae (Collembola, Entomobryidae) based on mitochondrial genomes. Zoologica Scripta 49 (3): 329-339. https://doi.org/10.1111/zsc.12408

Guthrie J.E. 1903. The Collembola of Minnesota. Zoological Series IV, Geological and Natural History Survey of Minnesota, Minneapolis, Minnesota. https://doi.org/10.5962/bhl.title.1701

Hüther W. 1986. New aspects in taxonomy of Lepidocyrtus (Collembola). In: Dallai R. (ed.) $2^{\text {nd }}$ International Seminar on Apterygota: 61-65. University of Siena, Siena.

Jordana R. 2012. Synopses of Palaearctic Collembola: Capbryinae \& Entomobryini. Soil Organisms 84 (1): 1-390.

Jordana R., Arbea J.I., Simón C. \& Luciáñez M.J. 1997. Fauna Iberica, Vol. 8. Collembola Poduromorpha. Museo Nacional de Ciencias Naturales, Madrid.

Katoh K. \& Standley D.M. 2013. MAFFT multiple sequence alignment software version 7: improvements in performance and usability. Molecular Biology and Evolution 30 (4): 772-780.

https://doi.org/10.1093/molbev/mst010 
Katz A.D. 2017. A new endemic species of Willowsia from Florida (USA) and descriptive notes on all New World Willowsia (Collembola: Entomobryidae). Zootaxa 4350 (3): 549-562.

https://doi.org/10.11646/zootaxa.4350.3.7

Katz A.D., Giordano R. \& Soto-Adames F.N. 2015a. Operational criteria for cryptic species delimitation when evidence is limited, as exemplified by North American Entomobrya (Collembola: Entomobryidae). Zoological Journal of the Linnean Society 173 (4): 810-840. https://doi.org/10.1111/zoj.12220

Katz A.D., Giordano R. \& Soto-Adames F. 2015b. Taxonomic review and phylogenetic analysis of fifteen North American Entomobrya (Collembola, Entomobryidae), including four new species. ZooKeys 525: 1-75. https://doi.org/10.3897/zookeys.525.6020

Kawada R. \& Buffington M.L. 2016. A scalable and modular dome illumination system for scientific microaphy on a budget. PLoS ONE 11 (5): 1-20. https://doi.org/10.1371/journal.pone.0153426

Kozlov A.M., Darriba D., Flouri T., Morel B. \& Stamatakis A. 2019. RAxML-NG: a fast, scalable and user-friendly tool for maximum likelihood phylogenetic inference. Bioinformatics 35 (21): 4453-4455. https://doi.org/10.1093/bioinformatics/btz305

Lanfear R., Frandsen P.B., Wright A.M., Senfeld T. \& Calcott B. 2017. PartitionFinder 2: New methods for selecting partitioned models of evolution for molecular and morphological phylogenetic analyses. Molecular Biology and Evolution 34 (3): 772-773. https://doi.org/10.1093/molbev/msw260

Lubbock J. 1873. Monograph of the Collembola and Thysanura. Ray Society, London. https://doi.org/10.5962/bhl.title.11583

Mari-Mutt J.A. 1979. A revision of the genus Dicranocentrus Schött (Insecta: Collembola: Entomobryidae). Agricultural Experiment Station Bulletin 259: 1-79.

Maynard E.A. 1951. A Monograph of the Collembola or Springtail Insects of New York State. Comstock Publishing Company, Inc., Ithaca, New York.

Nunes R.C., Godeiro N.N., Pacheco G., Liu S., Gilbert M.T.P., Alvarez Valin F., Zhang F. \& Bellini B.C. 2019. The discovery of Neotropical Lepidosira (Collembola, Entomobryidae) and its systematic position. Zoologica Scripta 48 (6): 783-800. https://doi.org/10.1111/zsc.12377

Porco D., Bedos A., Greenslade P., Janion-Scheepers C., Skarżyński D., Stevens M.I., Jansen van Vuuren B. \& Deharveng L. 2012. Challenging species delimitation in Collembola: cryptic diversity among common springtails unveiled by DNA barcoding. Invertebrate Systematics 26: 470-477. https://doi.org/10.1071/IS12026

R Core Team. 2020. R: A Language and Environment for Statistical Computing. R Foundation for Statistical Computing, Vienna, Austria. Available from (https://www.R-project.org/) [accessed 5 May 2020]

Rambaut A., Drummond A.J., Xie D., Baele G. \& Suchard M.A. 2018. Posterior summarisation in Bayesian phylogenetics using Tracer 1.7. Systematic Biology 67 (5): 901-904.

https://doi.org/10.1093/sysbio/syy032

Ronquist F., Teslenko M., Van Der Mark P., Ayres D.L., Darling A., Höhna S., Larget B., Liu L., Suchard M.A. \& Huelsenbeck J.P. 2012. MrBayes 3.2: efficient Bayesian phylogenetic inference and model choice across a large model space. Systematic Biology 61 (3): 539-542.

https://doi.org/10.1093/sysbio/sys029

Scott H.G. 1991. Springtails. In: Gorham S.J. (ed.) Insect and Mite Pests in Food: an Illustrated Key. Part 2: 351-361. Agriculture Handbook 655, United States Department of Agriculture, Washington, D.C. 
Shoebotham J.W. 1917. Notes on the Collembola, part 4. The classification of the Collembola; with a list of genera known to occur in the British Isles. Annals and Magazine of Natural History series 19: 425-436. https://doi.org/10.1080/00222931709486959

Skarżyński D., Piwnik, A. \& Porco D. 2018. Integrating morphology and DNA barcodes fro species delimitation within the species complex Xenylla maritima (Collembola: Hypogastruridae). Arthropod Systematics \& Phylogeny 76 (1): 31-43.

Soto-Adames F.N. 2002. Molecular phylogeny of the Puerto Rican Lepidocyrtus and Pseudosinella (Hexapoda: Collembola), a validation of Yoshii's "color pattern species". Molecular Phylogenetics and Evolution 25 (1): 27-42. https://doi.org/10.1016/S1055-7903(02)00250-6

Soto-Adames F.N. 2008. Postembryonic development of the dorsal chaetotaxy in Seira dowlingi (Collembola, Entomobryidae); with an analysis of the diagnostic and phylogenetic significance of primary chaetotaxy in Seira. Zootaxa 1683 (1): 1-31. https://doi.org/10.11646/zootaxa.1683.1.1

Stach J. 1967. Collembola fauna of Malta. Acta Zoologica Cracoviensia 12 (15): 393-418.

Sun X., Zhang F., Ding Y., Davies T.W., Li Y. \& Wu D. 2017. Delimiting species of Protaphorura (Collembola: Onychiuridae): integrative evidence based on morphology, DNA sequences and geography. Scientific Reports 7: 8261. https://doi.org/10.1038/s41598-017-08381-4

Szeptycki A. 1979. Chaetotaxy of the Entomobryidae and its phylogenetical Significance. Morphosystematic Studies on Collembola. IV. Polska Akademia Nauk, Karków.

Yoshii R. \& Suhardjono Y.R. 1992. Collembolan fauna of Indonesia and its affinities III: Collembola of Timor Island. Acta Zoologica Asiae Orientalis 2: 75-96.

Yosii R. 1959. Studies on the Collembolan fauna of Malay and Singapore with special reference to the genera: Lobella, Lepidocyrtus and Callyntrura. Contributions from the Biological Laboratory Kyoto University 10: 1-65.

Yu D., Qin C., Ding Y., Hu F., Zhang F. \& Liu M. 2018. Revealing species diversity of Tomocerus ocreatus complex (Collembola: Tomoceridae): integrative species delimitation and evaluation of taxonomic characters. Arthropod Systematics \& Phylogeny 76 (1): 147-172.

Zhang F. \& Deharveng L. 2015. Systematic revision of Entomobryidae (Collembola) by integrating molecular and new morphological evidence. Zoologica Scripta 44 (3): 298-311.

https://doi.org/10.1111/zsc. 12100

Zhang F., Palacios-Vargas J.G. \& Chen J.-X. 2007. The genus Willowsia and its Mexican species (Collembola: Entomobryidae). Annals of the Entomological Society of America 100 (1): 36-40.

https://doi.org/10.1603/0013-8746(2007)100[36:TGWAIM]2.0.CO;2

Zhang F., Chen J.-X. \& Deharveng L. 2011. New insight into the systematics of the Willowsia complex (Collembola: Entomobryidae). Annales de la Société entomologique de France 47: 1-20.

https://doi.org/10.1080/00379271.2011.10697692

Zhang F., Bedos A. \& Deharveng L. 2014a. Disjunct distribution of Szeptyckiella gen. nov. from New Caledonia and South China undermines the monophyly of Willowsiini (Collembola: Entomobryidae). Journal of Natural History 48 (21-22): 1299-1317. https://doi.org/10.1080/00222933.2013.859317

Zhang F., Chen Z., Dong R.R., Deharveng L., Stevens M.I., Huang Y.H. \& Zhu C.D. 2014b. Molecular phylogeny reveals independent origins of body scales in Entomobryidae (Hexapoda: Collembola). Molecular Phylogenetics and Evolution 70: 231-239. https://doi.org/10.1016/j.ympev.2013.09.024 
Zhang F., Yu D., Luo Y., Ho S.Y.W., Wang B. \& Zhu C. 2014c. Cryptic diversity, diversification and vicariance in two species complexes of Tomocerus (Collembola, Tomoceridae) from China. Zoologica Scripta 43 (4): 393-404. https://doi.org/10.1111/zsc.12056

Zhang F., Sun D.D., Yu D.Y. \& Wang B.X. 2015. Molecular phylogeny supports S-chaetae as a key character better than jumping organs and body scales in classification of Entomobryoidea (Collembola). Scientific Reports 5: 1-12. https://doi.org/10.1038/srep12471

Zhang F., Pan Z., Wu J., Ding Y., Yu D. \& Wang B. 2016. Dental scales could occur in all scaled subfamilies of Entomobryidae (Collembola): new definition of Entomobryinae with description of a new genus and three new species. Invertebrate Systematics 30 (6): 598-615.

https://doi.org/10.1071/IS16005

Zhang F., Ma Y. \& Greenslade P. 2017. New Australian Paronellidae (Collembola) reveal anomalies in existing tribal diagnoses. Invertebrate Systematics 31 (4): 375-393. https://doi.org/10.1071/IS16073

Zhang F., Yu D., Stevens M.I. \& Ding Y. 2018. Colouration, chaetotaxy and molecular data provide species-level resolution in a species complex of Dicranocentrus (Collembola: Entomobryidae). Invertebrate Systematics 32:1298-1315. https://doi.org/10.1071/IS18019

Zhang B., Chen T.-W., Mateos E., Scheu S. \& Schaefer I. 2019. DNA-based approaches uncover cryptic diversity in the European Lepidocyrtus lanuginosus species group (Collembola: Entomobryidae). Invertebrate Systematics 33 (4): 661-670. https://doi.org/10.1071/IS18068

Manuscript received: 13 May 2020

Manuscript accepted: 10 December 2020

Published on: 16 March 2021

Topic editor: Nesrine Akkari

Desk editor: Marianne Salaün

Printed versions of all papers are also deposited in the libraries of the institutes that are members of the EJT consortium: Muséum national d'histoire naturelle, Paris, France; Meise Botanic Garden, Belgium; Royal Museum for Central Africa, Tervuren, Belgium; Royal Belgian Institute of Natural Sciences, Brussels, Belgium; Natural History Museum of Denmark, Copenhagen, Denmark; Naturalis Biodiversity Center, Leiden, the Netherlands; Museo Nacional de Ciencias Naturales-CSIC, Madrid, Spain; Real Jardín Botánico de Madrid CSIC, Spain; Zoological Research Museum Alexander Koenig, Bonn, Germany; National Museum, Prague, Czech Republic. 